\title{
Anatomical Imaging for Radiotherapy
}

\author{
Philip M Evans, \\ Joint Physics Department, \\ Institute of Cancer Research and Royal Marsden NHS Foundation Trust, \\ Downs Road, Sutton, Surrey, SM2 5PT, UK
}

Author for correspondence:

Philip Evans, Joint Physics Department, Royal Marsden Hospital, Downs Road, Sutton, Surrey, SM2 5PT, UK

Tel: $\quad+442086613349$

Fax: $\quad+442086433812$

Email: phil.evans@icr.ac.uk

Running title: Anatomical Imaging for Radiotherapy

Number of words: $\quad 14000$

Number of references:304

Number of figures: 9

Number of tables: 1

Keywords:

Radiation therapy, imaging, treatment planning, treatment verification 


\begin{abstract}
The goal of radiation therapy is to achieve maximal therapeutic benefit expressed in terms of a high probability of local control of disease with minimal side effects. Physically this often equates to the delivery of a high dose of radiation to the tumour or target region whilst maintaining an acceptably low dose to other tissues, particularly those adjacent to the target. Techniques such as intensity modulated radiotherapy (IMRT), stereotactic radiosurgery and computer planned brachytherapy provide the means to calculate the radiation dose delivery to achieve the desired dose distribution. Imaging is an essential tool in all state of the art planning and delivery techniques: i) to enable planning of the desired treatment, ii) to verify the treatment is delivered as planned and iii) to follow up treatment outcome to monitor that the treatment has had the desired effect. Clinical imaging techniques can be loosely classified into anatomic methods which measure the basic physical characteristics of tissue such as their density and biological imaging techniques which measure functional characteristics such as metabolism. In this article we consider anatomical imaging techniques. Biological imaging is considered in an accompanying article.
\end{abstract}

Anatomical imaging is generally used for goals i) and ii) above. Computed tomography (CT) has been the mainstay of anatomical treatment planning for many years, enabling some delineation of soft tissue as well as radiation attenuation estimation for dose prediction. Magnetic resonance is fast becoming widespread alongside CT, enabling superior soft tissue visualisation. Traditionally scanning for treatment planning has relied on the use of a single snapshot scan. Recent years have seen the development of techniques such as 4D CT and adaptive radiotherapy (ART). In 4D CT raw data is encoded with phase information and reconstructed to yield a set of scans detailing motion through the breathing, or cardiac, cycle. In ART a set of scans is taken on different days. Both allow planning to account for variability intrinsic to the patient. Treatment verification has been carried out using a variety of technologies including: MV portal imaging, $\mathrm{kV}$ portal/fluoroscopy, MVCT, conebeam $\mathrm{kVCT}$, ultrasound and optical surface imaging. The various methods have their pros and cons. The four x-ray methods involve an extra radiation dose to normal tissue. The portal methods may not generally be used to visualise soft tissue, consequently they are often used in conjunction with implanted fiducial markers. The two CT based methods allow measurement of inter-fraction variation only. Ultrasound allows soft tissue measurement with zero dose but requires skilled interpretation and there is evidence of systematic differences between ultrasound and other data sources, perhaps due to the effects of the probe pressure. Optical imaging also involves zero dose, but requires good correlation between the target and the external measurement and thus is often used in conjunction with an x-ray method.

The use of anatomical imaging in radiotherapy allows treatment uncertainties to be determined. These include errors between the mean position at treatment and that at planning (the systematic error) and the day to day variation in treatment setup (the random error). Positional variations may also be categorised in terms of inter- and intra-fraction errors. Various empirical treatment margin formulae and intervention approaches exist to determine the optimum strategies for treatment in the presence of these known errors. Other methods exist to try to minimise error margins drastically including the currently available breath hold techniques and the tracking methods which are largely in development. This paper will review anatomical imaging techniques in radiotherapy and how they are used to boost the therapeutic benefit of the treatment. 


\section{Contents}

1. Introduction

2. Imaging and treatment uncertainties

3. Anatomical imaging in treatment planning

$3.1 \quad$ Computed tomography

3.1 .1

3.1 .2

3.1 .3

3.1 .4

3.1 .5

Target Delineation

CT Number Calibration

3.1 .6

3.2

3.2.1

3.2 .2

3.2 .3

3.2 .4

3.3 Image Acquisition Methods in the Presence of Motion Adaptive Radiotherapy

CT Perfusion

Metal-induced Artefacts

Magnetic resonance

Target Delineation

Image Distortion Correction

Treatment Planning Using MRI Alone

MRI Contrast Enhanced, Perfusion and Diffusion Imaging

4. Anatomical imaging in verification

$4.1 \quad$ Megavoltage portal imaging

$4.2 \quad$ Kilovoltage portal imaging

$4.3 \quad$ Kilovoltage CT

$4.4 \quad$ Megavoltage CT

4.5

4.6

4.7

5. Conclusions 
It is a very sad thing that nowadays there is so little useless information Oscar Wilde

\section{Introduction}

Modern radiotherapy uses high technology to try to achieve optimal local tumour control whilst minimising treatment side effects to an acceptably low level. Aspects of the technology used for this goal include: computer systems for three dimensional treatment planning and simulation, with accurate radiation dose deposition models and facilities for optimisation of external radiation beam or brachytherapy source distribution; computer controlled linear accelerators with dynamic beam collimation systems for external beam treatment, or systems such as remote afterloading for brachytherapy; and the use of radiation response models to characterise treatment outcome and to enable the prediction of treatment outcomes for future patients' treatments.

One of the cornerstones of the whole radiotherapy process is the use of information obtained from images. Imaging is needed at every stage of the whole treatment process to measure various aspects of the region of the patient being treated. The information obtained from the imaging may be used to diagnose the disease and to stage it, it may be used to provide input data for the treatment planning process, it may be used at the time of treatment to monitor the accuracy of the treatment (i.e. to ensure that the delivery of the radiation dose is anatomically correct), and it may be used to monitor response to treatment. Thus imaging information obtained about the patient is vital to essentially every stage of the radiotherapy process.

Imaging methods in radiotherapy may generally be grouped into two types. The first group is made up of those methods that provide anatomical information, that is the amount of tissue in the beam but not the status of that tissue, i.e. whether it is viable or not. Examples include conventional computed tomography (CT) and magnetic resonance imaging (MRI). CT produces a map of x-ray attenuation coefficients at the energy used to perform the scan, which with appropriate scaling, gives a good approximation to density. MRI most commonly gives a proton density map of the tissue. The second group are those imaging methods that measure some functional or biological aspect of the tissue being imaged. Examples include radionuclide imaging such as single photon emission tomography (SPECT) or positron emission tomography (PET) and magnetic resonance spectroscopy (MRS). This review discusses only the application of anatomical imaging in radiotherapy. Biological, or functional, imaging is considered in the accompanying review by Grosu and Bortfeld (Grosu and Bortfeld 2008). Dynamic contrast imaging with CT, MRI and other modalities might be argued to be anatomical and functional. For simplicity these applications are considered in this review rather than the accompanying one.

Whilst imaging information is used to determine the location of tissue to be treated to high radiation dose and, to a great extent, the value of that dose, the imaging process has limitations that need to be considered. Firstly, when imaging to define the tumour position and extent, the skill of the observer is important in delineating tumour from adjacent normal tissue. This is a task which can be extremely difficult as shown by variations between imaging techniques and between observers using the same technique. Also a given image only represents a snapshot of the patient's anatomy and the position of that anatomy. Thus consideration is needed that the imaging 
information has uncertainty associated with it, in regard to how typically a picture it paints of the position of tissues during treatment, with respect to variations between planning scans and treatment, day to day variations during treatment and movement effects during a single treatment visit. Other uncertainties exist with regard to how clearly the edges of target and non-target tissues may be determined in the image. Often these sources of uncertainties are accounted for by using geometric margins, the nature of which depend on the type of uncertainty to be accounted for (McKenzie et al 2000, 2002, van Herk 2004).

The use of imaging for cancer diagnosis and staging is a huge area worthy of review in itself and in the limited space of this review the focus will be on the use of anatomical imaging once the diagnosis and staging process has been completed. Firstly the relationship between imaging, organ localisation, errors and treatment margins will be discussed. The next process to be considered is that of treatment planning with anatomical imaging, in which, most commonly, CT and MR data are used to localise the tumour, then margins for error are defined around the localised tumour to produce a target and finally external radiation beams, or brachytherapy source positions, are designed to produce the desired dose distribution. Then how anatomical imaging contributes to the process of treatment verification, in which the anatomical positioning accuracy and dosimetric accuracy of the treatment must be measured (and ideally corrected) for each treatment fraction is reviewed. The measurement of treatment outcome using imaging is a large area, in which biological imaging is playing a greater part. This is beyond the scope of this review.

\section{Imaging and treatment uncertainties}

The purpose of anatomical imaging in radiotherapy is to determine the position of the target, either to localise and delineate it in the planning stage, or to verify it during treatment. The snapshot provided by a single image may not be accurate for all stages during the treatment course. Of the various errors present in radiotherapy, several of them are attributable to the limitations of the process of planning a treatment based on imaging information which involves skilled interpretation and which is obtained before treatment:

1. The anatomical image contains no functional information, hence if the density of tumour and normal tissue is similar in the image, definition of the tumour may be difficult.

2. The anatomy in the planning image may not be completely indicative of the anatomy during treatment. This may be the result of a change in patient weight or a positional different between the planning scan and the mean treatment position. Both of these lead to a systematic error in the treatment (Hurkmans et al. 2001, van Herk 2004).

3. There are stochastic variations in position from day to day in fractionated external beam treatment. Anatomical imaging may be used to measure and/or correct for these inter-fraction treatment errors (Hurkmans et al. 2001, van Herk 2004).

4. Particularly in the case of treatment in the thorax, intra-fraction variations may occur as a result of processes such as the breathing and cardiac cycles. Imaging may be used to characterise the resultant pattern of motion, so that treatment strategies can be designed to account for it (Seppenwoolde et al. 2002, 2007, Shirato et al. 2004b, 2006). 
5. Time trends may occur in fractioned treatments. This may be due to weight change or the response of tissue to radiation (El Gayed 1993, Hector et al. 2000, McDermott et al. 2006). The treatment should ideally respond to such changes.

The various errors have different effects on the treatment and thus may have to be dealt with differently.

On the whole, the distributions of systematic and random inter-fraction variations are thought to be stochastic and follow a Gaussian distribution (McKenzie et al 2000, van Herk 2004). Simulation techniques have been used to calculate margins needed to achieve a desired treatment accuracy (minimum percentage volume receiving a minimum dose level when summed over all treatment fractions) as a function of the systematic and random error distribution (Stroom et al. 1999, van Herk et al. 2000). These show the systematic error to be approximately three times as important as the random component. Correction strategies have been developed to reduce set-up margins. These fall into two categories: online protocols, in which both systematic and random errors are reduced by imaging with a test dose at the start of each treatment fraction and correcting set-up based on anatomical position (De Neve et al. 1992, Ezz et al. 1992, Gildersleve et al. 1994); and offline, in which a set of images are acquired to determine the systematic error component, which is then corrected at the next fraction. Various offline protocols have been developed, including shrinking action level (SAL) and no action level (NAL) (Bel et al. 1993, de Boer and Heijmen 2001, 2007).

The data for breathing motion are generally not normally distributed. Often the distribution has a minimum in the centre, with maxima at exhale and inhale and shows variability from cycle to cycle (Ford et al. 2002a). Thus it is distinctly nonGaussian. However, the fact that the treatment is fractionated ameliorates the problem in that a consequence of the central limit theorem is that the average over a sufficient number of fractions (typically 30) is Gaussian (Bortfeld et al. 2002). This requires that the breathing phase is asynchronous with the treatment delivery system. Nevertheless treatment errors may still ensue due to the fact that a single (or a few) snapshot of the breathing distribution is sampled when anatomical images are obtained for planning. This may introduce systematic treatment errors unless sufficient imaging data is acquired to describe the breathing distribution (Evans et al. 2006a). Another potential source of error is in the case of IMRT delivery with small segment doses, which can lead to beating between the patient motion and beam segment delivery (Seco et al. 2007). The complexity of intra-fraction motion has lead to a variety of approaches to its management, including using large margins to encompass its extent, breath hold, both voluntary and controlled (Lu et al. 2000, Wong et al. 1999, Remouchamps et al. 2003, Hanley et al. 1999, Mageras and Yorke 2004), treatment delivery gating (Kubo and Hill 1996, Shirato et al 2000b, Minohara et al. 2000) and delivery tracking (McQuaid and Webb 2006).

This discussion has focused on the relationship between the accuracy and quantity of the information from anatomic imaging and the margins for error needed. It should be emphasised that whilst good anatomical imaging for treatment planning and verification helps control many of these errors, there are many sources of error (and hence components of the treatment margins) that are not identifiable solely with anatomic imaging. Examples include the use of biological imaging to define the gross 
tumour volume (GTV) (ICRU 50 and 62, Grosu et al. 2005). Biological imaging may also improve definition of the margin to determine the clinical target volume (CTV). In the nomenclature of ICRU report 62, the set-up margin (SM) may include nonanatomical components, such as small differences in the co-ordinate frame used in the treatment machine and the treatment planning system (Van Herk 2004).

That aside, anatomical imaging has been used to achieve GTV definition and to monitor the treatment in various stages to allow small SM and internal margin (IM) parameters. A major challenge is to obtain sufficient information to characterise the behaviour of tumour and nearby normal tissues in the presence of the types of variations listed at the start of this section.

\section{Anatomical imaging in treatment planning}

Tumour definition is the first stage in the treatment planning process. Traditionally, this has been carried out for some treatment sites using planar x-ray imaging. With the advent of volumetric imaging (Hounsfield 1973, Mansfield 2004) and the development of methods of achieving complex dose distributions (Brahme 1988, Webb 1989, 2000), three dimensional planning using volumetric information is now commonplace. In the chain of processes in a radiotherapy treatment, tumour definition is the most critical. It is often the link in the chain with the biggest uncertainty and, by the very nature of tumour definition, is a process usually carried out once, and consequently any errors at this stage propagate systematically throughout the whole treatment (Van Herk 2004).

Often the outline of the tumour is delineated manually on the imaging data, relying on skilled interpretation to distinguish tumour from non-tumour tissue with low often low contrast and unclear boundaries. Studies have evaluated the accuracy of this process by comparing outlines produced by sets of observers to measure interobserver variability, and repeated outlines by a single observer to measure intraobserver variability, with results showing large variation in some cases. Methods of improving the variability in outlining have included combining different types of images, such as CT and MRI, and functional imaging such as PET. The combination of imaging methods in multimodality imaging requires registration of the various imaging datasets in the frame of reference of the treatment. Many approaches exist in the literature, from rigid body registration to deformable morphing of datasets. In addition fiducial markers, either external to the patient, or implanted close to the tumour have been used either to aid image registration or to improve accuracy of delineation in a single modality. Multimodality imaging is generally used to improve delineation of a static target by combining information.

Other approaches exist to ameliorate the target definition problem. These include the use of fixation systems and implanted markers. Fixation systems include external systems such as treatment site dependent boards (Creutzberg et al. 1993), evacuated beam bags (Nalder et al. 2001) and frames (Gill et al. 1991) and internal systems such as catheters (Fransson et al. 2002) and obturators (Merrick et al. 1999). Implanted markers may be fiducial gold grains which may be implanted using a biopsy needle (in the case of sites such as the prostate) (Crook et al. 1995). Surgical clips may also be used at time of surgery (in the case of the breast) (Machtay et al. 1994, Marks et al. 1994). 
The effects of anatomical variations, both day-to-day and intra-fraction, may be measured by the acquisition of multiple data sets from the same modality. Day-to-day variations may be measured using repeat scans in a process known as adaptive radiotherapy or ART (Yan et al. 1998). Intra-fraction variations, such as breathing effects, may be measured in CT by scanning sufficiently slowly to encompass the whole breathing cycle, but this introduces distortion to the image dataset. Alternatively, it may be measured using 4D imaging, in which data is acquired throughout the breathing cycle, with a measurement of the breathing phase so that the data may be sorted into different breathing phases to measure these variations.

\subsection{Computed tomography}

X-ray computed tomography (CT) has been a key component of radiotherapy diagnosis and planning from the time it was introduced into clinical practice in the early 1970s. A thorough review of x-ray computed tomography may be found in Kalender (2006). CT was the first imaging modality to offer detailed imaging of internal anatomy in three dimensions and thus to allow accurate determination of the spatial location of target tissues relative to non-target tissues.

It's role has evolved with the use of CT scans to calculate the attenuation of the treatment radiation (from an external beam or internal source) and the resultant dose distribution in the treatment planning process, along with the generation of reference image data for treatment verification in external beam treatment. These reference images, known as digitally reconstructed radiographs (DRRs), are projection x-ray images generated from the treatment planning computer (Sherouse et al. 1990) and may be compared with film or electronic portal images (EPI) for each treatment fraction.

\subsubsection{Target delineation}

The primary purpose of CT scanning in radiotherapy is to enable delineation of the treatment target. This is often a difficult manual task and probably still the main source of inaccuracy in radiotherapy (Webb 1993). It is often difficult to obtain a ground truth measurement of tumour location and manual outlining is the most common method of delineation. Thus the accuracy of the delineation process is usually described in several ways: intra-observer outlining variations, inter-observer variations, differences between imaging methods (such as between CT and MR and between CT and biological imaging (Grosu and Bortfeld 2008)). The results are treatment site dependent. Here we summarise a few findings from the literature. A more detailed review of volumetric uncertainty in radiotherapy may be found in Hamilton and Ebert (2005).

One of the earliest studies of outlining variation was for the prostate and seminal vesicles (Fiorino et al. 1998). Five well trained radiotherapists contoured CT images of 6 patients scanned in the supine position. Outlining of one patient was repeated immediately to measure short-term intra-observer variability. The outlined volumes (referred to as inserted volumes) were estimated from lateral and antero-posterior projections in the beams eye view. Intra-observer variability was relatively small, with an average variation of 5\% 1 standard deviation (SD). Inter-observer variation was larger $10-80 \% 1 \mathrm{SD}$. Variations were largest for the lateral margins of the prostate and seminal vesicles and the top and bottom of the prostate. 
Inter-observer variability in lung tumour delineation has been studied by Van de Steene et al. (2002). Five clinicians outlined the gross tumour volume (GTV) on CT scans of eight patients. The GTVs were compared in terms of the volume drawn and judgement of lymph node invasion. Clinical relevance of variations was evaluated using dose calculations in conformal treatment plans. The results showed interobserver variations in tumour extent of between 2.8 and $7.3 \mathrm{~cm}$. After common review of the lymph node status, it was found that there were $37 \%$ false negative and $22 \%$ false positive diagnoses, affecting the target volumes outlined.

Chang et al. (2002) evaluated intra- and inter-observer variability for nasopharyngeal carcinoma. 13 patients were outlined by two trained observers. They found small differences between observers except in two cases with involvement of the paranasal sinuses. Weiss et al. (2003) evaluated target delineation by five radiation oncologists and two gynaecologists for three patients with cervical carcinoma. The ratio between largest and smallest volumes ranged between 3.6-4.9 and 1.3-2.8 for the radiation oncologists and for the gynaecologists respectively. The ratio of common volume to maximal encompassed volume (essentially the Jaccard similarity index (Tan et al. 2005)) was respectively $0.11-0.13$ and $0.30-0.57$. Mukherji et al. (2005) evaluated interobserver variability for eight experienced observers outlining the GTV in squamous cell carcinoma of the supraglottic larynx. They found good agreement between the observers with a correlation coefficient of 0.81 .

\subsubsection{CT number calibration}

A CT scan is a map of attenuation coefficient at the energy of the scanner's x-ray tube, which may typically be between $80 \mathrm{kVp}$ and $150 \mathrm{kVp}$. Data are often displayed as Hounsfield units, with air assigned a value of 0 and water 1000 units. The dose calculation algorithms used in planning radiotherapy involve determining attenuation of the treatment beam or treatment radiation in the tissue of the phantom or patient, with correction for variations in tissue type (Cassell et al. 1981). Algorithms currently used include Monte Carlo (Reynaert et al. 2001, Verhaegen and Seuntjens 2003), collapsed cone kernels (Ahnesjö 1989) and pencil beam kernels (Gustafsson et al. 1994). The variations in tissue type are modelled with density corrections such as the equivalent path length model (O'Connor 1957, Sontag and Cunningham 1978, Ahnesjö and Aspradakis 1999). A lookup table is often used in the treatment planning system to scale data taken at the CT scanner energy to yield attenuation coefficient at the treatment energy (Henson and Fox 1984), which in external beam radiotherapy, is often in the megavoltage range. The photoelectric effect is significant at the CT scan energies and negligible at the megavoltage energies, with the Compton effect dominating.

The values for this lookup table are usually measured with a calibration phantom consisting of inserts of different densities. Often the lookup table is expressed as two or three linear regions (Seco and Evans 2006). The different balance between photoelectric effect and Compton scattering in the two energy ranges is accounted for in this process. The first approaches to using kilovoltage energy CT data for megavoltage therapy planning were published in the late 1970s (Kijewski and Bjarngard 1978 and Parker et al. 1979). More recent work has refined this scaling, particularly in the context of accurate Monte Carlo treatment planning (Verhaegen and Devic 2005, Reynaert et al. 2007). Refinements have included determination of the effects of variations in hydrogen content and extension to higher energies, where 
pair production becomes important (Seco and Evans 2006). The conversion of Hounsfield numbers to stopping powers for hadron therapy has been discussed by several authors (Chen et al. 1979, Mustafa and Jackson 1983, Schneider et al. 1996). Schneider et al used a stoichiometric approach to generate a table of proton stopping power as a function of electron density and Hounsfield number for a range of tissues of biological interest. Their results showed changes in hydrogen content are also important for calibration for hadron dose calculation.

\subsubsection{Image acquisition methods in the presence of motion}

As discussed above the acquisition of a scan for treatment planning purposes represents a single snapshot of patient anatomy. Developments of the technology since the first demonstration of $\mathrm{CT}$ have included faster data acquisition and reconstruction time, with scanner rotation times now under half a second (Kalender 2006) and real-time reconstruction becoming possible with fast computers. In addition the advent of multi-slice scanners has enabled the imaging of large anatomical volumes in the time of a single rotation. Often the scanner operates in helical mode (Kalender et al. 1989) for multi-slice acquisition. A major advantage of helical scanning over sequential slice acquisition is that moving objects (such as the heart or the breathing lungs) may be imaged continuously with a corresponding control of the resultant motion artefacts. At the time of writing 64 and 128 slice scanners represent the state of the art. Ultimately it is expected a whole region of the body may be imaged with a single rotation (Lewis 2001). An alternative approach to the use of multiple fan slices is cone-beam CT, using a two-dimensional detector (Feldkamp et al. 1984) rather than a stack of one-dimensional detectors. This approach is particularly finding application for treatment verification (Jaffray et al. 1999) as discussed later in this article. Advantages of the cone-beam approach include potentially shorter acquisition times to image a volume. Disadvantages include greater difficulty in generating a scan calibrated in Hounsfield numbers due to the great scatter component compared to the more conventional multiple slice detectors (Siewerdsen and Jaffray 2001). These improvements in scanner technology allow data acquisition with one or a few breath holds for imaging in the presence of lung motion (Kubo and Hill 1996).

Whilst imaging with breath hold greatly reduces motion artefacts in imaging mediastinum and lung tumours and is expected to aid diagnosis, it does not represent an ideal solution for treatment planning. External beam radiotherapy treatments generally take several minutes, during which a single breath hold is not possible. Several breath holds could be used but questions exist about the reproducibility of multiple breath holds (Wong et al. 1999, Cheung et al. 2003). Also there is the need for synchronisation to treatment delivery (Kubo and Hill 1996). Technological developments are expected to ameliorate this problem, however, as treatment linac dose rates increase, partly due to the development of beams without flattening filters (Mackie et al. 1999). In the case of brachytherapy a similar situation exists in that the treatment takes place over many breathing cycles.

An approach to generate $\mathrm{CT}$ data that is more representative of the distribution of tissue during the treatment is the use of a slow CT scan (Lagerwaard et al. 2001, Wurstbauer et al. 2005), the purpose of which is to sum over the motion in the breathing cycle and create in image showing the full tumour extent. Lagerwaard et al. evaluated slow CT in comparison with conventional fast spiral scanning. Three 
conventional scans were also acquired during quiet expiration for 10 patients with peripheral lung tumours. Slice thickness was $3 \mathrm{~mm}$, with reconstruction index 2.5 $\mathrm{mm}$. Three slow CT scans were acquired at 4 s/slice (slice thickness $4 \mathrm{~mm}$, reconstruction index $3 \mathrm{~mm}$ ). The images were registered and several measurements were made of the similarity of the volumes. In all cases the slow scan volume was larger than the conventional volume with an average increase of $14 \%$. Slow CT was also found to be more reproducible. For each scan type, the ratio of the common overlapping volume to the volume encompassed by all three CTVs was evaluated (the Jaccard index). Values for this index of $54.9 \% \pm 12.9 \%$ and $62.6 \% \pm 10.8 \%$ were found for conventional fast and slow CT respectively, indicating the slow scans to be more reproducible.

Whilst slow CT used in this manner may improve over conventional, fast CT, it has the potential disadvantage in that it smears out the effects of movement, providing a motion envelope but not a temporal description of that motion. Four dimensional computed tomography (4DCT) aims to measure the detailed motion of the tumour and thus to generate the probability density function of that motion, which may be used to improve treatment accuracy in several ways:

1. To determine the centre of mass of the motion distribution and allow the minimisation of the margin needed to account for that motion (Wolthaus et al. 2006, Bortfeld et al. 2002, Evans et al. 2006a);

2. To allow gating of the treatment in a particular phase of the breathing cycle (Balter et al. 1998, Minohara et al. 2000, Vedam et al. 2001, Ford et al. 2002a, Ozhasoglu et al. 2002)

3. To allow tracking of treatment delivery (Webb 2005, McQuaid and Webb 2006, McClelland et al. 2007).

4DCT is used to acquire a detailed motion model of the patient's anatomy and particularly of the tumour for lung, oesophagus, liver and breast treatment. The currently available alternative techniques are subject to artefacts in the presence of breathing which 4DCT helps to avoid (Rietzel et al. 2005a, 2005b, Jiang 2006). Consider a conventional scan of a breathing object, in which the scanner moves from top to bottom of the object when acquiring data. If the motion speed and scan speed are similar, then beating effects may occur. This has been illustrated by Rietzel for scanning of a moving sphere (figure 1, Rietzel et al. 2005b). Depending on the synchronisation between the scanner and the object, the sphere may appear distorted, or as a set of disjointed objects. In the case of slow CT discussed above, the object distribution is convolved with the motion distribution to yield a blurred estimate. The use of such images for radiotherapy treatment planning results in a distorted target volume and hence a distorted dose distribution.

The requirement of 4DCT is to acquire raw data, often in a spiral scan geometry (or using the slow scan method), and to measure the position in the breathing cycle as the data are acquired (Ford et al. 2002a, Low et al. 2003, Keall 2004a, Underberg et al. 2004, Van der Geld et al. 2006, Lu et al. 2006b). This approach often involves using the cardiac gating input signal to the CT scanner (see for instance Ohnesorge et al. 2000). The data are binned into subsets based on breathing position and reconstructed separately to yield a set of snapshot images. Several methods of measuring position in the breathing cycle have been developed. Measurement of external anatomy has been used, including fluoroscopic video imaging of a marker placed on the skin, reported 
by Wagman et al. (2003) and Keall et al. (2004b). One of the first examples of this includes the real-time position management (RPM) system which utilises a marker incorporated into a block placed on the patient surface outside the treatment field, which is illuminated with infrared and the reflected light detected with a camera (Ford et al. 2002a, Wagman et al. 2003). Zhao et al. (2007) have reported the use of an optical surface imaging system. Low et al. (2003) used a spirometer. Wolthaus et al. (2005) used a thermometer placed in the breathing airflow in the patient's nostrils. Several authors have used strain gauges (Ohara et al. 1989). Kubo and Hill (1996) made a comparison of the accuracy of various techniques, including a thermistor, a thermocouple, a strain gauge and a pneumotachograph. Movies were acquired at X-ray simulation using each method along with the reading from each candidate gating system. The temperature sensor and strain gauge were judged the preferred systems based on characteristics such as reproducibility, accuracy, response speed and signal to noise ratio.

The respiratory signal used to acquire a 4DCT data set may also be used to acquire a CT scan at a single breathing phase. The treatment would be planned and delivered at this breathing phase. This would require both CT scanner and treatment room to have similar equipment for measuring the patient's breathing phase. Mageras and Yorke (2004) evaluated the use of respiratory gating for treatment in comparison with deep inspiration breath-hold (DIBH). They found that approximately half their patients could not comply with DIBH and hence there was the need to screen potential patients. The respiratory gating used the RPM system. The disadvantages of the DIBH approach were that it required active patient participation (hence the problem with patients being able to comply) and a breath hold is tolerable for a much shorter time than the several minutes taken by a radiotherapy fraction delivery or for a functional imaging procedure such as positron emission tomography. The use of treatment gating based on the external marker system was found still to require a level of patient effort and cooperation. Patients were coached verbally.

Patient coaching is often needed for both breath-hold and respiratory gated approaches to CT (including 4DCT) and for treatments planned based on their use. This is because breathing is subject to variability, examples of which may be a variation in respiratory period or a drift in position (Dawson et al. 2001, Seppenwoolde et al. 2002, Mageras and Yorke 2004). This must be minimised to reduce artefacts in scanning and, in treatment, to avoid systematic errors introduced by differences between planning and treatment.

When gating CT acquisition (either to obtain a scan in a single position or a 4D set of scans), the choice of how to define the gating position is important. This is based on when one breathing cycle ends and the next starts. The potential for variability in the breathing cycle makes this an important choice. Two main approaches have been discussed in the literature, phase gating and amplitude gating (Vedam et al. 2001, Shen et al. 2003, Mageras and Yorke 2004). In amplitude gating, acquisition is triggered when the breathing trace is in a certain position and in phase gating, triggering is based on when the breathing is at a given phase angle.

If a 4DCT data set is acquired, it is often desirable to register the position of anatomy between the various phases. The advantages of doing this include calculation of the summed dose distribution over the whole breathing cycle (Lujan et al. 1999, Coolens 
et al. 2006, Rietzel et al. 2006). Deformable motion models are generally necessary to achieve this, particularly as tumours of the lung and liver are soft tissues, prone to deformation (see e.g. Balter et al. 1996). The main approaches adopted for application to radiotherapy planning is the use of B-splines interpolants (Rueckert et al. 1999, Hartkens et al. 2002). Deformable motion models have been used for CT registration in a different context. Christensen et al. (2001) presented an approach to combining dosimetry for external beam and intracavity brachytherapy. Three patients with locally advanced cervical cancer were treated with CT-compatible applicators and underwent five CT scans: before the start of external beam treatment and before and after two brachytherapy insertions. Data sets were registered using a viscous fluid flow model. Results were analysed in terms of a coincidence index (equivalent to the Jaccard index) and found the deformable registration to yield a range 90.6-100\% compared with 5.2-72.2\% without registration. A detailed review of these and other methods for deformable image registration may be found in Hill et al. (2001).

The 4DCT approach generally involves establishing the mean trajectory of the target over several breathing cycles. This information is then used to plan the treatment strategy, but may be subject to variability. Information on the variability has been sought in two ways: by the use of fluoroscopy (Chen et al. 2001) and by data modelling (Land et al. 2007). Low et al. (2005) developed a 5-dimension model of lung motion, as a combination of tidal volume and airflow components to describe the motion of a set of points as a function of breathing cycle. For the cases they studied, they were able to fit the motion of the points with an average discrepancy of $0.75 \mathrm{~mm}$.

\subsubsection{Adaptive radiotherapy}

The gating and 4DCT approaches described above are expected to be particularly valuable for sites where intra-fraction motion is important, such as the lung or liver. Other sites, such as the prostate or bladder, are expected to be more prone to interfraction, or day to day, variation. Again a single scan constitutes a single snapshot image which may not be indicative of the anatomy throughout the patient's treatment.

Yan and colleagues (Yan et al. 2000, Martinez et al. 2001) have proposed a method called adaptive radiotherapy (ART) which seeks to ameliorate this problem by obtaining a set of CT scans of the patient on different days at the start of treatment and designing the target volume using the extra information from this set of scans and electronic portal imaging (EPI) on each treatment day. The method was applied to prostate cancer patients. In the report by Martinez, 150 patients had an initial CT scan from which a treatment plan was made. On the first four days of treatment, CT scans and EPI data were obtained. These were used to generate a confidence limited planning target volume (cl-PTV) (see figure 2, Martinez et al. 2001). The CT scans were first registered to correct for day to day positional variations using bony anatomy. To generate the cl-PTV, the convex hull of the extent of the PTV was then constructed. The effects of better definition of PTV were modelled to determine the dose escalation achievable whilst satisfying dose constraints specified for the rectal wall. The conclusion was that ART allowed 5\% dose escalation for conformal radiotherapy and $7.5 \%$ escalation for IMRT.

Pos et al. (2006) have evaluated ART for bladder treatment. For a group of 21 patients, 5 daily CT scans were acquired immediately before or after irradiation (randomly selected to avoid bias), during the first week of treatment and used to 
construct the cl-PTV (referred to as PTV $\mathrm{ART}_{\mathrm{ART}}$ ). A treatment plan based on this was used from the third week and further CT scans taken to measure the accuracy of ART. The results were quantified in terms of the treatment volume reduction achievable with ART and showed a $40 \%$ saving compared with conventional.

\subsubsection{CT perfusion}

The problems of target delineation may be reduced by the use of functional imaging, particularly in tumours expected to show an enhancement or detriment in uptake relative to adjacent normal tissues. This may be from a biological imaging modality such as PET (Grosu and Bortfeld 2008) or a contrast agent in a modality such as CT or MRI. Contrast agents are starting to be used more frequently in CT scanning for radiotherapy planning, particularly for the head and neck region. There is the need to consider bulk correction to the CT numbers in the region of the contrast agent for accurate dose calculation purposes. The effect of contrast agent on dose calculation accuracy has been investigated. Choi et al. (2006) measured the effect of intravenous contrast agent on IMRT dose planning for head and neck cancer. Fifteen patients each had two scans, one before contrast agent injection and one after. Target volumes and organs at risk were contoured on the contrast enhanced scan and IMRT plans created. The beams of the plan were copied onto the non-contrast enhanced scans and the dose distribution recalculated. Target dose values for the enhanced scans were found to be significantly lower than on the non-enhanced scans, but the dose differences were less than $1 \%$. Dose to parotid glands and spinal cord were not found to be significantly different.

Perfusion measurement involves imaging a time sequence following the rapid intravenous bolus injection of a contrast agent (Axel 1980). A review of perfusion CT may be found in Miles and Griffiths (2003). One of the most significant studies of perfusion CT is the work of Hermans et al. $(1999,2003)$ for head and neck cancer. In the first of their studies (1999) they investigated variability (both intra- and interpatient and intra- and inter-observer) and the value of perfusion as a predictive factor of local failure after radiotherapy treatment for 41 patients. They found no significant difference between measurements performed by two independent observers. No correlation between perfusion rate and tumour volume was found. No significant correlation between perfusion rate and local control $(p=0.19)$ was found for the patient number studied. In the 2003 study, they evaluated perfusion as a predictive factor for local and regional failure in 105 head and neck patients. They stratified the patients according to the mean perfusion value and found those with the lower perfusion rates had a significantly higher local failure rate $(\mathrm{p}<0.05)$. An example of a perfusion study is shown in figure 3 (Newbold et al. 2005, Castellano 2006). Fig 3a shows a CT slice through the head and neck region, with various regions of interest identified and $3 \mathrm{~b}$ shows the temporal Hounsfield number change follow administration of iodine contrast agent (Newbold et al. 2005, Castellano 2006).

Contrast enhanced CT has found particular use in brain imaging (e.g. Nabavi et al. 1999, Hakime et al. 2007). In radiotherapy, Sidhu et al. (2004) considered delineation of brain metastases for radiosurgery treatment planning. They studied the effect of the timing between administration of the contrast agent and imaging on the measured volume of the lesion. Ten patients were given Omnipaque 300 contrast agent and scanned immediately following bolus injection and again with a delay of median value $65 \mathrm{~min}$. Results showed an increase in the volume of the metastases in $86 \%$ of 
cases and the consequent choice of a larger collimator. In the case of two metastases contrast was no longer visible in the delayed scan. No significant intra- or interobserver variability was found. They concluded that the study showed the importance of the imaging protocol in the use of contrast enhanced CT.

\subsubsection{Metal-induced artefacts}

Metal body implants include artificial limbs, particularly hips (Coolens and Childs 2003), and fiducial markers implanted to aid target definition. By nature of their high attenuation of the kilovoltage X-ray source in the CT scanner they produce artefacts that can cause problems in the use of CT data for radiotherapy planning. Firstly the attenuation takes the raw signal outside the range at which the Hounsfield unit calibration is valid and hence affects dose calculation, and secondly streak artefacts from the implant obscure useful soft-tissue structures that may help in target volume definition. Various approaches have been taken to reduce the effects of these artefacts. Examples include calibration of the CT scanner response by an electron density correction (Hensen and Fox 1984) and the use of the stoichiometric method of Schneider as described above (Schneider et al. 1996, Coolens and Childs 2003). Others have developed filters applied to the raw sonogram data or to the reconstructed data (Bal and Spies 2006). Figure 4 (Bal and Spies 2006) shows a CT scan of a prostate patient with implanted fiducial markers. The image is shown with and without a filter to reduce the severity of the streak artefacts.

\section{2}

\section{Magnetic resonance imaging}

Magnetic resonance imaging (MRI) has become an important imaging modality in radiotherapy planning, complementing the use of CT. It provides several advantages over CT, including improved soft tissue visualisation and hence better target delineation; it is fundamentally 3D (rather than a stack of $2 \mathrm{D}$ slices as in CT); and novel techniques are available such as cine MR and magnetic resonance spectroscopy (MRS). Disadvantages include the lack of an attenuation correction map for dose planning; geometric distortion; and cost. MRS is a biological imaging modality and so not within the remit of this review. A detailed review of MRS in radiotherapy treatment planning may be found in Payne and Leach (2006).

\subsubsection{Target delineation}

Several studies have evaluated MRI for target volume definition and often the results have been expressed in terms of comparison between MRI and CT volumes and their treatment planning consequences.

For the prostate, MRI and CT were compared by Roach et al. (1996). Ten patients were scanned with T1 weighted MRI and CT (without the use of contrast agent). The bony anatomy on the images was matched and the measured prostate volumes (excluding seminal vesicles) compared. Retrograde urethrograms were used to assist with definition of the inferior border of the prostate (Roach et al. 1993). The mean prostate volume was found to be $32 \%$ larger on average (range -5-63\%) for CT. Discrepancies in volume definition were associated with four regions in the prostate: the posterior part, the posterior-inferior-apical part; difference in apex position between the urethrogram and MRI; and regions corresponding to the neurovascular bundle. They discussed using contrast enhancement in the CT scan as an alternative. Rasch et al. (1999) compared MRI and CT for delineation of prostate and seminal vesicles in 18 patients. Proton density MRI scans were taken in axial, coronal and 
sagittal planes and compared with CT. As with Roach's study, the CT volumes were found to be larger, in this case by $43 \%(\mathrm{p}<0.005)$ for axial scanning. Axial MRI volumes were, on average, found to be 1.09 and 1.19 times the coronal and sagittal volumes, respectively. Systematic differences between the positions of the apex of the prostate and seminal vesicles were evaluated, with both found to be 6-7 $\mathrm{mm}$ closer to the centre of the prostate on the axial MRI scans, with coronal MRI scans agreeing to within 1.5-3 $\mathrm{mm}$ on average. Variability between three observers was measure and found to be a smaller factor than choice of scan modality. They recommended axial MR should be used for delineation, with a combination of axial and coronal scans in case of doubt, and the CT scan used for treatment plan dose calculation. Debois et al. (1999) found broadly similar results using T2 weighted axial and coronal MRI data, with the average CT volume $46 \%$ bigger than on axial MRI for 9 patients, plus one patient showing a larger volume on MRI than on CT. Inter-observer variability in the location of the apex was measured for three observers and found to be best for coronal MRI and worst for CT. The effect on planned dose to rectum was compared for the modalities and it was found that the volume of rectum on the MRI scan receiving more than $80 \%$ of the prescribed dose was reduced by $23.8 \%$ on average compared with CT organ delineation. Jackson et al. (2007) found a 14\% bigger prostate volume for CT (11 patients) and that the planned percentage of rectum treated to doses above 45Gy (prescribed treatment dose 70Gy) was significantly lower for T2-weighted MRI compared to CT. Khoo and Joon (2006) reviewed new developments in MRI for target volume delineation. Figure 5 (from Khoo and Joon) shows a CT slice through a patient's prostate and the corresponding T2-weighted MRI slice, revealing better visualisation of organ boundaries.

MRI has the advantage that rapid images may be acquired without the dose associated with cine CT. An example of the use of this in radiotherapy is the evaluation of rectal distension and rectal movement on prostate position using cine MRI (Padhani et al. 1999). 55 patients were scanned axially using a T1-weighted spoiled gradient-echo sequence and a T1-weighted turbo-FLASH sequence every $10 \mathrm{~s}$ for $7 \mathrm{~m} .24$ patients received bowel relaxants before imaging. Rectal movements were seen in 51\% patients overall. A smaller percentage of those receiving relaxants showed movement, but the result was not statistically significant. Incidence of rectal movement correlated with degree of rectal distension, but the magnitude of that movement did not. The rectal movements correlated well with prostate movement. Prostate movements in the anterior-posterior direction were seen in $29 \%$ patients and in $16 \%$ of patients the movement was greater than $5 \mathrm{~mm}$. The conclusions of the study were that rectal movements result in displacements that are significant in magnitude for radiotherapy planning over a time period similar to the delivery of a radiotherapy fraction.

Ten Haken et al. (1992) evaluated MRI delineation of brain tumours in 15 patients (5 with low grade astrocytomas and 10 with higher grade glial tumours). The datasets used consisted of CT scans with iodinated intravenous contrast, and a variety of MRI scans: axial T2 weighted, axial T1 weighted and coronal T1 weighted. The T1 weighted scans were taken with gadolinium contrast. Two components to the target volume were defined on each imaging modality: a microscopic volume defined by edema on CT and increased T2 signal on MRI; and a macroscopic/boost volume defined by contrast enhancement on CT and T1-weighted MRI. MRI defined volumes (both microscopic and macroscopic) were larger than for CT. The composite volume, defined as the sum of CT and MRI, had just 50-55\% overlap between CT and MRI. 
The PTV (made by expanding the microscopic volume by $2 \mathrm{~cm}$ in all direction and the macroscopic volume by $1 \mathrm{~cm}$ ) showed greater overlap with $79 \%$ and $69 \%$ respectively. Weltens et al. (2001) studies interobserver variability in brain tumour definition, combining CT and MRI for five patients with inoperable supratentorial tumours. Nine physicians participated in the study. A larger variation in outlining was found. Figure 6 (from Weltens et al. 2001) shows an example GTV delineation variation between the observers for the two modalities. The ratio of largest to smallest CT GTV volume outlined was between 1.7 and 2.8. Use of MRI plus CT still produced a large variation in the volume ratio - between 1.5 and 2.4. The volumes delineated on the combined scan data was on average $17 \%$ higher than on $\mathrm{CT}$ alone.

Other treatment sites where MRI target definition has been evaluated include base of skull meningiomas (Khoo et al. 2000), central nervous system (Aoyama et al. 2001) and liver (Teefey et al. 2003).

\subsubsection{Image distortion correction}

Imaging data for radiotherapy treatment planning should have good geometric accuracy, as distortion will contribute to systematic errors in the positioning of tissues and potentially dose calculation errors. It is well known that MRI system suffer from geometric distortions due to issues such as variations in magnetic field strength, gradient field non-linearity and susceptibility effects. Distortions have been shown to range from typically 0.2 to $5 \mathrm{~mm}$ as the distance from the centre of the magnetic field increases from 5 to $10 \mathrm{~cm}$ Prott et al. (2000). For these reasons there is much interest in quantifying this distortion, establishing its effect on treatment dosimetric accuracy and developing methods to correct for it.

Kooy et al. (1994) demonstrated the use of chamfer matching to fuse CT and MRI for radiosurgery planning. They presented two cases, an acoustic neurinoma and a pilocytic astrocytoma. They concluded that MRI is necessary in stereotactic therapy, with superior diagnostic quality, but with poor geometric fidelity. Prott et al. (2000) investigated the effects of MRI distortion on radiotherapy treatment planning. They investigated $27 \mathrm{MRI}$ units. The distortions were found to cause small variations in maximum dose $( \pm 0.5 \%)$. Changes in the $95 \%$ isodose volume were seen $(25 \%$ cases showed an increase and 60\% a decrease). Organ at risk doses variations were found to be comparable to those in the PTV.

Several groups have evaluated methods of distortion correction for treatment planning. Tanner et al. (2000) described the removal of MRI system distortions using a geometric phantom consisting of orthogonal arrays of water-filled polymethylmethacrylate tubes. Figure 7 shows an uncorrected coronal image of the phantom. Results showed that distortions were over $10 \mathrm{~mm}$ for larger distances off axis. Reproducibility of the measurements was of order $0.1 \mathrm{~mm}$ indicating the accuracy expected from such a calibration procedure. Most current clinical MRI systems have $1.5 \mathrm{~T}$ field strength. Petersch et al. (2004) evaluated distortion in a $0.2 \mathrm{~T}$ system and its effects on treatment planning. They found that using the phantom calibration method to remove system effects reduced maximum distortion from 28.0 to $13.7 \mathrm{~mm}$ with mean distortion reduced from 2.2 to $0.6 \mathrm{~mm}$ and $95 \%$ of points with distortion of less than $1.5 \mathrm{~mm}$. Object induced distortions were also investigated and found to be a second order effect. Wang et al. (2004a, 2004b, 2004c) studied geometric distortion in several models of MRI systems. They measured distortion 
using a purpose built phantom consisting of a 3D grid of crosses. They found similar results to other investigators, with maximum distortion errors between 10 and $25 \mathrm{~mm}$ and corrected images accurate to better than $0.8 \mathrm{~mm}$.

\subsubsection{Treatment planning using MRI alone}

In treatment sites without significant tissue inhomogeneity, there is the potential to use MRI alone for treatment planning, with a bulk density correction applied for dose calculation in the absence of an electron density map from CT. This has been investigated for prostate cancer (Lee et al. 2003, Petersch et al. 2004). For a 1.5T system, Lee showed distortions of $2 \mathrm{~mm}$ in the vicinity of the prostate for FLASH 3D T1-weighted images and that the use of bulk density assignment to water and bone produced treatment plans with similar percentage volumes of rectum receiving greater than $50 \%$ dose to CT for conformal treatment. The plan to extend this work to T2weighted imaging, with greater contrast, was discussed. Petersch investigated the use of the $0.2 \mathrm{~T}$ resistive MRI system discussed above. Dose calculations, with all tissues taken as water equivalent, showed agreement with $\mathrm{CT}$ of $1 \%$ in the dose at the normalisation point in four out of five cases studied.

\subsubsection{MRI contrast enhanced, perfusion and diffusion imaging}

MRI perfusion and diffusion imaging have been evaluated for imaging cancer. A review of the underlying physical principles may be found in Thomas et al. (2000).

Rouviere et al. (2004) evaluated gadolinium dynamic contrast enhanced (DCE) MRI versus T2-weighted MRI for localisation of intraprostatic lesions in 22 patients. They correlated their findings with biopsy results and measured variability between three observers. The DCE imaging produced better agreement with biopsy and better interobserver agreement than the T2-weighted images. Storaas et al. (2004) also evaluated DCE MRI for prostate localisation. 28 patients were imaged with gadolinium DCE T1-weighted 3D echo planar imaging and a T2-weighted turbo spin echo (TSE) sequence. Comparison was also made with histology from resected specimens. No statistically significant improvement in localisation of prostate or seminal vesicles was found by adding the DCE information and they concluded that the DCE sequence did not improve tumour localisation compared to the T2-weighted sequence.

Sumi et al. (2003) evaluated the use of diffusion-weighted MRI to detect metastatic cervical lymph nodes in head and neck cancer patients. Diffusion-weighted echo planar imaging and T1- and T2-weighted MR imaging sequences were performed on a set of patients' lymph nodes. The results were correlated with histology. The apparent diffusion coefficient (ADC) was found to be significantly greater in metastatic lymph nodes than in benign lymphadenopathy $(\mathrm{P}<0.01)$, with nodal lymphomas having the lowest ADC values. Applying an ADC criterion for detection of metastatic nodes yielded a negative predictive value of $71 \%$ and a positive predictive value of $93 \%$. A fuller review of diffusion MRI to assess cancer therapeutic efficiency may be found in Chenevert et al. (2000).

MRI perfusion has been used to study blood flow in brain tumours (Cha et al. 2002, Keston et al. 2003). Wenz et al. (1996) compared perfusion in low grade astrocytomas and normal brain tissue before and after radiotherapy. Results showed a significant reduction in blood volume within the tumours after irradiation, with an insignificant 
reduction for gray and white matter outside the target volume. By comparison a significant reduction in blood volume for gray and white matter was observed after whole-brain irradiation, suggesting perfusion MRI may be used to monitor tumour response and normal tissue effects in radiotherapy.

\subsection{Ultrasound}

Ultrasound has been used to assist target definition in treatment planning, particularly in the absence of CT data. Some of these applications are being replaced by CT and MRI, but the development of new technology, including 3D scanning (Treece et al 2003) and tissue characterisation imaging (Burnside et al. 2007) mean that ultrasound has a important contribution to anatomical imaging for radiotherapy planning. Ultrasound has been used in several target localisation studies for post-lumpectomy breast radiotherapy. DeBiose et al. (1997) demonstrated localisation of the lumpectomy cavity for interstitial brachytherapy; Helyer et al. (1999) investigated the determination of the depth of the tumour bed and consequent selection of electron boost energy, and Coles et al. (2007) made a comparison of 2D and 3D ultrasound with CT for localisation of the tumour bed. They concluded that co-registration of 3D ultrasound with planning $\mathrm{CT}$ data can be used to yield additional information on the size and position of the tumour bed to be incorporated into the planning volumes. Featherstone et al. (1999) used ultrasound to localise the ovaries for radiation-induced ovarian ablation as part of breast cancer treatment. Orecchia et al. (2007) used ultrasound to measure the treatment of prostate cancer with intraoperative radiotherapy (IORT). 11 patients were treatment with pelvic lymphadenectomy, prostate IORT (with an electron beam from a mobile linear accelerator) and radical retropubic prostatectomy. Prostate thickness and depth of rectum were measured with ultrasound and used to quantify the dose distribution to the prostate and rectum.

Real-time transrectal ultrasound (TRUS) has been used to enable image-guided source implantation in brachytherapy treatment of localised prostate cancer (Blasko et al. 1993, 1995, Hoskin and Bownes 2006, Lawton et al. 2007). Blasko et al. presented a method for transperineal permanent implantation of ${ }^{125} \mathrm{I}$ and ${ }^{103} \mathrm{Pd}$ seeds. In their method, they took a set of transverse ultrasound images covering the prostate volume and determined the optimum seed distribution. The seeds were then implanted under biplanar ultrasound guidance to enable the operator to visualise needle placement in both transverse and sagittal planes and to see prostate movement. Post-implantation, a CT scan was taken to enable dose calculation. They contrasted their method with the older retropubic approach and concluded that better dose homogeneity, greater reproducibility and a larger treatment volume are achievable with the new method. 469 patients were treated with the image-guided technique. Follow up for a median time of 37 months showed favourable prostate-specific antigen (PSA) levels. Lawton et al. (2007) recently presented results of a multi-centre, phase 2 study, in which 95 patients were treated with the ultrasound-guided transperineal method. Patients were followed up for a mean time of 5.3 years. Survival at 5 years was $96.7 \%$. $6 \%$ had biochemical failure. They concluded that the outcome results were comparable to other brachytherapy data and the results of surgery and external beam radiotherapy.

Ultrasound guidance has also been used to aid source implantation in brachytherapy of gynaecological malignancies. Stock et al. (1997) presented the use of TRUS imageguided for a series of cases (4 cervical, 2 endometrial and 1 vaginal). Sahinler et al. (2004) demonstrated the use of transvaginal ultrasound guidance for placement of 
tandem applicators for cervical cancer treatment. The ultrasound scan was used to judge the likely difficulty of applicator insertion and found to have good predictive value.

\section{Anatomical imaging in verification}

Anatomical imaging for treatment verification is an essential part of the radiotherapy process. Recent years have seen significant technological development of a number of complementary approaches to this problem. The essential goal of treatment verification is to minimise and quantify any differences between the treatment as planned and delivered. Quantification of differences is in terms of the geometrical errors discussed above and ultimately the dose distribution and predicted impact on treatment outcome. The use of imaging of soft-tissue for verification, particularly in external beam radiotherapy, is often referred to as image guided radiotherapy (IGRT) verification (Jaffray 2007) or target of the day (Mackie et al. 1999). The term IGRT has also been used in terms of planning using functional imaging (Chao et al. 2001) and using imaging dynamically in a procedure (Zamorano et al. 1987) such as the TRUS methods discussed in the previous section.

A wide variety of techniques have been applied to IGRT, including:

1. Megavoltage $\mathrm{x}$-ray electronic portal imaging (EPI)

2. Kilovoltage $\mathrm{x}$-ray portal imaging

3. Kilovoltage CT (most commonly conebeam, but also $\mathrm{CT}$ on rails in the treatment room)

4. Megavoltage CT (including Tomotherapy)

5. Electromagnetic marker tracking

6. Ultrasound

7. Optical methods

The portal imaging methods, 1 and 2, being projection based, are good for imaging bony structure. In order to determine soft-tissue positioning, they are generally used in conjunction with surrogate, fiducial markers. Thus they are invasive, but have the potential to be used for tracking intra-fraction motion if sufficiently rapid data can be acquired. The CT methods, 3 and 4, involve pre-treatment scanning, allow soft tissue visualisation, facilitate adaptive radiotherapy and provide information similar to the data used to plan the treatment. They are useful for determining inter-fraction variations. The first four methods all entail extra dose to non-target tissues in the patient (except the use of megavoltage portal imaging of the delivered beam). Electromagnetic tracking, ultrasound and optical imaging entail no extra dose. Electromagnetic marker tracking provides a real-time 3D movement map of implanted fiducials. Ultrasound allows soft tissue visualisation but requires a skilled operator, scanner set-up and may be prone to tissue distortion from the probe pressure. Optical systems are completely non-contact, but only allow surface imaging and hence must be used with imaging of internal anatomy and/or a model of the relationship between motion of internal and external anatomy. The utility of ultrasound and optical imaging are treatment site dependent. Megavoltage portal imaging and the two $\mathrm{CT}$ methods may be used to provide treatment dosimetry estimation. A summary of some of the properties of these imaging methods is presented in table 1. Newer verification techniques are being developed including the incorporation of an MRI scanner into the external-beam treatment machine (Raaymakers et al. 2004). 


\subsection{Megavoltage portal imaging}

Several excellent reviews of megavoltage EPI have been written (Boyer et al. 1992, Herman et al. 2001, Langmack 2001, Antonuk 2002, Herman 2005, Kirby and Glendinning 2006). EPI has the attraction that it images the actually treatment beam (hence may involve no extra dose) and provides some information on internal anatomy. The fact that it provides projection images using higher x-ray energy limits the quality of the information available, however. Several imaging technologies have been applied to EPI (see the reviews of Boyer et al. and Antonuk), but the majority of currently used systems are based on amorphous silicon flat panel imagers (FPIs) (Antonuk et al. 1992), with one system based on a CCD camera (deBoer et al. 2000). FPIs are used for many of the alternative x-ray verification systems including kilovoltage portal imaging and conebeam CT (CBCT).

In terms of anatomical imaging, the information most commonly available is the position of bony anatomy relative to the radiation field edge. Hurkmans et al. (2001) made a thorough review of the literature on the measurement of random and systematic inter-fraction treatment errors for a variety of treatment sites: head and neck, prostate, pelvis, lung and breast. Soft tissue imaging has been achieved using implanted fiducial markers as a surrogate (Vigneault et al. 1997, Nederveen et al. 2002, 2003, Ford et al. 2002a, Aubin et al. 2003, Chen et al. 2007). Nederveen et al. (2003) compared the measurement of positional errors based on bony anatomy with the use of fiducial markers. They evaluated 2025 portal images in comparison with CT for 23 patients. Standard deviations in systematic marker position deviations of 2.4 to $4.4 \mathrm{~mm}$ were found. An offline correction protocol (Bel et al. 1993) reduced this to under $1 \mathrm{~mm}$. The use of bony anatomy in the correction protocol, in place of the fiducials, reduced the set-up error by $50 \%$ in two directions, but no reduction was found in the cranio-caudal direction. This study showed the value of the fiducial markers and that large set-up margins may still be needed if basing corrections bony anatomy. McDermott et al. (2006) showed how changes in anatomy could be determined using difference images. Examples presented include progressive changes in lung cancer patients in response to irradiation.

Other applications of EPI include dosimetry, which may be empirical measurement (Hansen et al. 1996, Pasma et al. 1999, McDermott et al. 2004, Greer 2005, Winkler et al. 2005, Wendling et al. 2006) or model based (Spies et al. 2000, McCurdy et al. 2001, Spezi et al. 2002, Siebers et al. 2004, Parent et al. 2006) and IMRT verification (Warkentin et al. 2003, Van Esch et al 2004, Wendling et al. 2006). Commercially available detectors have low quantum efficiency $(\mathrm{QE})$ at $1-2 \%$. Several groups are developing higher efficiency systems using approaches such as thick scintillators or structured high density material (Mosleh-Shirazi et al. 1998a, Pang and Rowland 2002, Sawant et al. 2002, 2005, Evans et al. 2006b) to increase the efficiency by an order of magnitude, with the challenge of maintaining spatial resolution.

\section{2}

\section{Kilovoltage portal imaging}

Kilovoltage projection imaging has long been used in radiotherapy in the x-ray treatment simulator. With the advent of CT simulation (see e.g. Nishidai et al. 1990) the role of the conventional simulator has changed and several groups have used simulator fluoroscopy to measure intra-fraction breathing motion. Malone et al. (2000) measured prostate motion using fiducial markers and Poggi et al. (2003) 
evaluated marker migration. Chen et al. (2001) and Sixel et al. (2003) evaluated tumour motion in lung patients. This was carried out without markers, based on image intensity. The purpose of such studies was to determine the margins needed to account for intra-fraction motion.

By incorporating diagnostic-energy $\mathrm{x}$-ray imaging into the treatment room, it is possible to acquire $\mathrm{kV}$ portal images for treatment verification. As early as $1985 \mathrm{a}$ diagnostic x-ray set was mounted on a treatment linac (Biggs et al. 1985). Several authors have compared MV and $\mathrm{kV}$ portal imaging for set-up correction (Jaffray et al. 1995, Pisani et al. 2000). The early studies were with film or camera based systems. These have been replaced by the FPI systems. Manufacturers are starting to provide $\mathrm{kV}$ imaging systems on the treatment unit to enable $\mathrm{kV}$ projection and CBCT imaging (Jaffray 2005, Yoo et al. 2006b). These are generally mounted at right angles to the treatment beam.

Systems with one $\mathrm{kV}$ imager provide 2D information. The combination with orthogonal MV imaging can provide 3D information. A favoured approach is to incorporate at least two $\mathrm{kV}$ systems to enable stereoscopic 3D imaging. Up to four systems are installed to enable imaging at gantry angles which might obscure one of the systems. These systems are often used in conjunction with implanted fiducial markers to enable tracking of mobile tumours, such as in the lung or liver.

The first example of this approach was in a robotic radiosurgery system (Adler et al. 1999, Murphy et al. 2003). This used two orthogonal, floor-mounted FPI detectors and ceiling mounted x-ray sets. Yin et al. (2002) reported the use of a similar system for intensity modulated radiosurgery of spinal tumours. Massachusetts General Hospital have also developed a system with two x-ray tubes mounted $45^{\circ}$ from the treatment head (Berbeco et al. 2004). These systems also use infrared tracking to complement the $\mathrm{x}$-ray systems and allow tracking between $\mathrm{x}$-ray verification images, thus reducing x-ray dose (Jiang 2006, Jin et al. 2007).

The group of Shirato (Shirato et al. 2000a, 2000b, 2004b, 2006, Shimizu et al. 2001, Seppenwoolde et al. 2002) developed a system with four floor-mounted x-ray tubes with ceiling-mounted $\mathrm{x}$-ray image intensifiers that imaged at 30 frames/s. A photograph of the system is shown in figure 8 . A $2 \mathrm{~mm}$ gold fiducial marker implanted in the body was imaged using $\mathrm{x}$-ray energies of 50 to $120 \mathrm{kVp}$. The dosimetric consequences of using this system in fluoroscopic mode for real-time tumour tracking were evaluated. The surface dose was found to be between 28 and $980 \mathrm{mGy} / \mathrm{h}$, depending on $\mathrm{kVp}$ and $\mathrm{x}$-ray pulse width (Shirato et al. 2004a).

\subsection{Kilovoltage CT}

Kilovoltage CT in the treatment room provides 3D anatomical information including soft tissue and thus provides advantages over the portal imaging methods described above. However the scan is generally obtained prior to therapy and hence has limited information on intra-fraction variations. Two approaches have been developed: the incorporation of a diagnostic CT scanner in the treatment room and the attachment of a kilovoltage source and FPI on the treatment linac and scanning in conebeam geometry (Feldkamp et al. 1984). 
The use of diagnostic scanners in the treatment room is achieved by moving the treatment couch between the treatment machine and the CT scanner and is often referred to as CT on rails. Court et al. (2003) evaluate the positional accuracy of such a system in terms of the component errors introduced by the need to move the couch. They evaluated two positioning protocols: one relying on the mechanical integrity of the system; and one using radio-opaque markers in the treatment couch. The first had positional accuracy of $0.6-0.7 \mathrm{~mm}$ and the second better than $0.5 \mathrm{~mm}$. This system is further described in Ma and Paskalev (2006). Kuriyama et al. (2003) evaluated an alternative system and found comparable accuracy of $0.4 \mathrm{~mm}$.

The duel-energy imaging system of Jaffray discussed above was used to take CBCT scans on the treatment unit, using an x-ray tube at $90^{\circ}$ to the treatment beam and a camera-based imager initially (Jaffray et al. 1999) and a FPI ultimately (Jaffray and Siewerdsen 2000, Jaffray et al. 2002). Ding et al. (2007) describe a similar system. Létourneau et al. (2005) demonstrated the use off the conebeam geometry to produce images with high spatial resolution in all three directions with a sagittal slice through a prostate patient showing good definition of bladder, prostate, seminal vesicles, rectum and sigmoid colon (see figure 9). One of the potential disadvantages of the conebeam geometry is the larger amount of scattered x-rays, which may increase noise in the reconstructed images and hence reduce detectability of low contrast objects (Endo et al. 2001). In addition it may be desirable to use the images for dosimetric verification, either by inputting the images to the dose calculation algorithm on the treatment planning system, or using a transit dosimetry approach (Hansen et al. 1996, McNutt et al. 1996). The scattered radiation may affect the Hounsfield number calibration, thus introducing uncertainty to the dose calculation (Malušek et al. 2005). Siewerdsen et al. (2004) demonstrated the use of anti-scatter grids and Jarry et al. (2006) demonstrated the use of a Monte Carlo based correction method, which improved calibration for a variety of phantom materials. Yoo and Yin (2006a) evaluated the dose planning accuracy of uncorrected images and showed that in most cases the error was below $1 \%$, with $3 \%$ error in an inhomogeneous phantom. Patient doses have been evaluated and found to be of order 1-3cGy (Islam et al. 2006, Amer et al. 2007). Solutions to problems identified in conventional CT have also been developed for CBCT, including metal artefact reduction (Zhang et al. 2007) and correction for respiratory motion (Sonke et al. 2005, Schreibmann et al. 2006). Several papers have demonstrated clinical applications of CBCT (Sykes et al. 2005, Henry et al. 2006, White et al. 2007, Létourneau et al. 2007).

\subsection{Megavoltage CT}

Megavoltage CT (MVCT) uses the treatment beam to make a scan and hence provides an alternative method of treatment-time $\mathrm{CT}$ without the need for additional X-ray sources or detectors. The first implementations used a single row of high QE elements comprised of photo-diodes and scintillators, scanned in third generation geometry (Simpson et al. 1982, Swindell 1983, Brahme et al. 1987, Nagakawa et al. 1991, Lewis et al. 1992). Later systems used conebeam geometry, either based on a high QE scintillator array coupled to a camera (Mosleh-Shirazi et al. 1998a, 1998b) or an FPI (Hesse et al. 1998, Ford et al. 2002b, Sillanpaa et al. 2005, Pouliot et al. 2005). One system has combined high QE with the use of an FPI (Seppi et al. 2003). Tomotherapy uses MVCT for verification (Mackie et al. 1999, Ruchala et al. 1999, 2000, Forrest et al. 2004, Meeks et al. 2005). The detector used is a high-pressure xenon ionisation chamber. 
The limitations of MVCT in comparison with diagnostic energy CT arise from the lower quantum efficiency of a detector at the megavoltage energy and the lower intrinsic contrast between the various tissues. However trade-offs may be made in terms of quantities such as the spatial resolution required, to limit the dose needed (Simpson et al. 1982). Advantages of MVCT over conventional CT include the reduction of artefacts due to high $\mathrm{Z}$ materials such as dental fillings (Pouliot et al. 2005, Lu et al. 2006a). Also as the images are attenuation maps in the treatment beam, MVCT may readily be used for treatment planning dose calculation and dose verification without the need for a conversion table as in conventional CT (Simpson et al. 1982, Aoki et al. 1990, Kapatoes et al. 2001, Langen et al. 2005, Morin et al. 2007). Yin et al. (2005) combined projections from $\mathrm{kV}$ and MVCT systems at $90^{\circ}$ to each other, with the potential to utilise the best features of both systems.

Meeks et al. (2005) presented a detailed characterisation of the Tomotherapy MVCT system. They showed images could be acquired with doses as low as 1.1 cGy (measured in a $20 \mathrm{~cm}$ diameter cylindrical phantom). Langen et al (2005) presented the use of this system for daily prostate localisation, comparing features in MVCT and planning CT scans. Sidhu et al. (2003) discussed correction of the treatment plan to account for the MVCT dose. Their system used an FPI to acquire 21 conebeam geometry projections at $10^{\circ}$ intervals, giving $52.5 \mathrm{cGy}$ in total. The dose level was determined by the requirement of the EPID to receive at least 2.5 cGy per projection. They showed good dose distributions could be achieved if the MVCT is considered in the plan optimisation for IMRT. Pouliot et al. (2005) used an FPI to achieve conebeam images with $0.02-0.08$ monitor units per projection, to produce images with between 5 and 15 cGy. Comparisons between MVCT and treatment CT scans were shown for a head and neck cancer patient. They also showed improvement in image quality by removing the flattening filter from the beam.

\subsection{Electromagnetic marker tracking}

An approach to the use of surrogate fiducial markers that does not require an x-ray dose is the use of implanted electromagnetic transponders (Balter et al. 2005, Willoughby et al. 2006, Kupelian et al. 2007, Litzenberg et al. 2007). The transponders used are larger than radio-opaque markers, being cylinders $8 \mathrm{~mm}$ long and $1.85 \mathrm{~mm}$ diameter (radio-opaque markers are typically $1 \mathrm{~mm}$ length e.g. Litzenberg et al. 2002) and are imaged, at a rate of $10 \mathrm{~Hz}$, with a magnetic array placed close to the patient surface. Balter et al. (2005) showed the system to provide submillimeter accuracy under a variety of conditions.

The use of this system has been demonstrated for prostate localisation. Willoughby et al. (2006) presented the first data resulting from imaging sets of 3 transponders implanted into 20 patients. For 11 of the cases, transponder measurements were compared with $\mathrm{kV}$ radiographic imaging of the transponders. The average 3D difference was $1.5 \pm 0.9 \mathrm{~mm}$. Patients were also tracked for 8 minutes and, in some cases, showed organ motion in excess of $1 \mathrm{~cm}$ for a large part of this period. Litzenberg et al. (2007) investigated the potential for marker migration for all 20 of these patients and showed that 58 of the 60 markers did not migrate, indicating similar long term stability to radio-opaque markers. 
Various ultrasound systems have been developed for soft-tissue verification in radiotherapy, with particular application to prostate localisation. The first systems to be implemented consisted of a B-mode trans-abdominal probe attached to a precision tracking arm (Huang et al. 2002, Chandra et al. 2003, Little et al. 2003, Trichter and Ennis 2003, Langen et al. 2003, Peignaux 2006). Real-time images were displayed, overlaid with outlines from the planning CT scan. The set-up error was determined by moving the outlines in sagittal and transverse directions until the ultrasound scans matched with them.

Several authors have evaluated the accuracy of such systems in comparison with EPI and have generally found differences. Trichter et al. found systematic shifts between the two imaging methods of typically $3 \mathrm{~mm}$ in each direction, with a large spread of values. Others have compared ultrasound position measurements with fiducial markers on EPI (Langen et al. 2003, Van den Heuvel et al. 2003). Again they show significant systematic differences. Langen reported differences between ultrasound and marker alignment of $0.2 \pm 3.7$ ( 1 standard deviation), $2.7 \pm 3.9$ and $1.6 \pm 3.1 \mathrm{~mm}$ in anterior-posterior, super-inferior and lateral directions respectively. They also found inter-observer variability in the use of the contour alignment system. The significant differences seen in these studies have been attributed to the effects of probe pressure distorting the prostate anatomy. Artignan et al. (2004) made a systematic study of this effect. Ten volunteers were imaged with a $3 \mathrm{D}$ probe fixed with a rigid arm, which was moved stepwise towards the prostate and further images obtained. The largest movement was seen in the posterior direction. A probe displacement of $1.2 \mathrm{~cm}$ was needed to get good image quality, resulting in an average prostate displacement of $3.1 \mathrm{~mm}$. McGahan et al. (2004) made a similar study and found similar results. Treece et al. (2002) have developed a method of correcting for probe pressure effects. Cury et al. (2006) compared two approaches to ultrasound verification using a 3D probe system. The first approached (named cross-modality) is equivalent to the techniques described above and the second involves measuring shifts by comparing ultrasound scans on different days. Significant differences were found $6 \mathrm{~mm}$ in the superior-inferior direction. They recommended the use of the second approach. Several automatic methods have been developed to outline the prostate in 3D ultrasound scans (Wang et al. 2003, Hu et al. 2003)

Although mostly used for prostate radiotherapy, studies of ultrasound localisation have been carried out in other sites. Coles et al. describe localisation of the tumour bed in breast radiotherapy using a 3D reconstruction method (Prager et al. 2002). The post-lumpectomy cavity was visible in all 3D ultrasound images. Comparison with $2 \mathrm{D}$ ultrasound showed the 3D system to be significantly superior.

With the advent of fast 3D scanners, several groups are developing real-time tracking systems (Pagoulatos 2001, Kolen et al. 2004). Two groups have discussed the use of such as system to gate treatment delivery (Sawada et al. 2004, Hsu et al. 2005). The ultimate goal of such approaches would be to gate treatment delivery based on intrafraction motion measurement.

\subsection{Optical methods}

Optical imaging may only provide information on the external anatomy, but may be completely non-invasive and requires zero dose. Its effective use requires knowledge of the relationship between the motion of the target and the external anatomy. Two 
basic types of system exist: those that use infrared imaging of localised reflective, or active, markers to track motion, and those that use video camera data, which may be used to measure surface outline or to track. One of the first systems developed used a plastic block with infrared markers (Ford et al. 2002a). Other systems use a set of markers (Soete et al. 2002, Marmulla et al. 2004) either attached to the patient's skin or to a holder. These systems are also often used to register the position in the treatment room of the ultrasound systems discussed above. Video systems to track motion have used correlation measurement (Yan et al. 2002). Video outlining has been achieved using stereoscopic measurement of the contour of the room laser on the patient surface (Wilks and Bliss 2002), feature-based CT outline matching (Ploeger et al. 2003) and stereoscopic imaging of a speckle pattern projected onto the patient surface (Moore et al. 2003, Schöffel et al. 2007). The intrinsic accuracy of such systems has been shown to be high, with the ability to measure patient shifts of under $1 \mathrm{~mm}$.

Gierga et al. (2005) evaluated the relationship between internal and external anatomy for liver patients, measured with fluoroscopy of implanted fiducial clips and radioopaque markers placed on the skin. Results showed the variation in tumour position for a given external marker position ranged between 2 and $9 \mathrm{~mm}$, illustrating the importance of using information on internal anatomy. A solution to this problem is to use external anatomy but to update its relationship with internal anatomy periodically using radiographic images (Kanoulas et al. 2007).

\section{Conclusions}

This review has focused on the use of anatomical imaging in radiotherapy, with the accompanying article discusses biological imaging. The combination of information from these complementary imaging modalities is expected to have great synergistic benefit for cancer treatment. This is of particular relevance for target definition, which remains the most important source of error in radiotherapy. Anatomical imaging with $\mathrm{CT}$ and MRI yield different gross tumour volumes. Functional imaging with modalities such as PET will generally reveal a different volume still. Thus a decision has to be made how to combine such information. In the absence of good histopathological information, or a proven quantitative biological imaging marker for clonogenic cell density, there is likely to be no gold standard imaging method for a particular treatment case.

Anatomical imaging techniques have an important role to play in image guided treatment verification. At present several methods are being used as described in the literature. A recent AAPM meeting (Pouliot et al. 2007) included a debate on the future of IGRT verification, discussing five approaches and finishing with a vote as to which method was going to be the 'winner'. Debates such as this are important, as they encourage discussion of the approaches to IGRT, but it is likely that the optimum solutions will be based on a combination of these approaches as each of the methods have advantages and disadvantages as presented in table 1. Another current area of discussion in IGRT verification is the dose associated with procedures such as kilovoltage conebeam CT. This was also debated at a recent conference (Van Herk and Lomax 2007). Kilovoltage CT is often considered to provide the best imaging information for IGRT, but the dose remains an issue for many, because it potentially involves significant extra skin dose, due to the low x-ray energy used, and delivers a bath of low dose to tissue outside the target, which may entail the risk of cancer 
induction. The consequences of this are disease site specific for several reasons. Firstly, the patient age, expected survival and quality of life and disease recurrence risk vary greatly with disease site and the judgement as to what extra imaging dose is acceptable has to consider these issues. In the case of disease sites where long term survival is expected to be good, an approach based on a combination of the zero extra dose methods and those that do require extra dose may be best. A risk adapted approach to verification is necessary in which a judgement is made as to the trade off between the risk of the extra dose and the risk of the level of inaccuracy without the use of that technique. This should include consideration of a multimodality approach to verification. A second site specific consideration is based on radiobiology. There is evidence that several common tumour types exhibit a low $\alpha / \beta$ ratio (Fowler et al. 2001, Yarnold et al. 2005). A consequence of this is that hypofractionation may become a more attractive treatment approach. In this case the dose associated with an $\mathrm{x}$-ray based scan becomes a smaller fraction of the total dose delivered in treatment, hence reducing the relative risk.

The past decade has seen significant advances in medical imaging and in the way imaging is used in radiation therapy. More information than ever may be obtained to assist in designing a patient's treatment, delivering and monitoring the accuracy of that treatment and to following its progress and quantify effectiveness. Debate still exists as to what information is sufficient and how best to harvest that information.

\section{Acknowledgements}

The permission granted by authors and journals to reproduce figures in this article is gratefully acknowledged. Useful discussions were had with Ellen Donovan, Mike Partridge and Steve Webb during the writing of this article. Rosemary Atkins provided valuable help with the formatting of the references. The work to produce figure 3 was carried out in collaboration with the Radiology Department, Royal Marsden NHS Foundation Trust, Sutton. The work of the radiotherapy physics group is partly funded by Cancer Research UK (under programme reference C46/A3970). 


\section{References}

Adler J R, Murphy M J, Chang S D and Hancock S L 1999 Image-guided robotic radiosurgery Neurosurgery 44 1299-1306

Ahnesjo A 1989 Collapsed cone convolution of radiant energy for photon dose calculation in heterogeneous media Med. Phys. 16 577-592

Ahnesjo A and Aspradakis M M 1999 Dose calculations for external photon beams in radiotherapy Phys. Med. Biol. 44 R99-R155

Amer A, Marchant T, Sykes J, Czajka J and Moore C 2007 Imaging doses from the Elekta Synergy Xray cone beam CT system Br. J. Radiol. 80 476-482

Antonuk L E 2002 Electronic portal imaging devices: a review and historical perspective of contemporary technologies and research Phys. Med. Biol. 47 R31-R65

Aoki Y, Akanuma A, Evans, PM Lewis DG, Morton EJ and Swindell W,1990, A dose distribution evaluation utilizing megavoltage CT imaging, Radiation Medicine - Medical Imaging and Radiation Oncology 8 107-110

Aoyama H, Shirato H, Nishioka T, Hashimoto S, Tsuchiya K, Kagei K, Onimaru R, Watanabe Y and Miyasaka K 2001 Magnetic resonance imaging system for three-dimensional conformal radiotherapy and its impact on gross tumor volume delineation of central nervous system tumors Int. J. Radiat. Oncol. Biol. Phys. 50 821-827

Artignan X, Smitsmans M H P, Lebesque J V, Jaffray D A, van Her M and Bartelink H 2004 Online ultrasound image guidance for radiotherapy of prostate cancer: Impact of image acquisition on prostate displacement Int. J. Radiat. Oncol. Biol. Phys. 59 595-601 1

Aubin S, Beaulieu L, Pouliot S, Pouliot J, Roy R, Girouard L M, Martel-Brisson N, Vigneault E and Laverdiere J 2003 Robustness and precision of an automatic marker detection algorithm for online prostate daily targeting using a standard V-EPID Med. Phys. 30 1825-1832

Axel I 1980 Cerebral blood-flow determination by rapid-sequence computed-tomography - a theoretical-analysis Radiology 137 679-686

Bal M and Spies L 2006 Metal artifact reduction in CT using tissue-class modeling and adaptive prefiltering Med. Phys. 33 2852-2859

Balter J M, Ten Haken R K, Lawrence T S, Lam K L and Robertson J M 1996 Uncertainties in CTbased radiation therapy treatment planning associated with patient breathing Int. J. Radiat. Oncol. Biol. Phys. 36 167-174

Balter J M, Lam K L, McGinn C J, Lawrence T S and Ten Haken R K 1998 Improvement of CT-based treatment-planning models of abdominal targets using static exhale imaging Int. J. Radiat. Oncol. Biol. Phys. 41 939-943

Balter J M, Wright J N, Newell L J, Friemel B, Dimmer S, Cheng Y, Wong J, Vertatschitsch E and Mate T P 2005 Accuracy of a wireless localization system for radiotherapy Int. J. Radiat. Oncol. Biol. Phys. 61 933-937

Bel A, Vanherk M, Bartelink H and Lebesque J V 1993 A verification procedure to improve patient set-up accuracy using portal images Radiother. Oncol. 29 253-260

Berbeco R I, Jiang S B, Sharp G C, Chen G T Y, Mostafavi H and Shirato H 2004 Integrated radiotherapy imaging system (IRIS): design considerations of tumour tracking with linac gantry-mounted diagnostic x-ray systems with flat-panel detectors Phys. Med. Biol. 49 243255

Biggs P J, Goitein M and Russell M D 1985 A diagnostic X-Ray field verification device for a 10 MV Linear-Accelerator Int. J. Radiat. Oncol. Biol. Phys. 11 635-643

Blasko J C, Grimm P D and Ragde H 1993 Brachytherapy and organ preservation in the management of carcinoma of the prostate Semin. Radiat. Oncol. 3 240-249

Blasko J C, Wallner K, Grimm P D and Ragde H 1995 Prostate-specific antigen based disease-control following ultrasound-guided (125) iodine implantation for stage T1/T2 prostatic-carcinoma $J$. Urol. 154 1096-1099

Bortfeld T, Jokivarsi K, Goitein M, Kung J and Jiang S B 2002 Effects of intra-fraction motion on IMRT dose delivery: statistical analysis and simulation Phys. Med. Biol. 47 2203-2220

Boyer A L, Antonuk L, Fenster A, Vanherk M, Meertens H, Munro P, Reinstein L E and Wong J 1992 A review of electronic portal imaging devices (epids) Med. Phys. 19 1-16

Brahme A, Lind B and Nafstadius P 1987 Radiotherapeutic computed-tomography with scanned photon beams Int. J. Radiat. Oncol. Biol. Phys. 13 95-101

Brahme A 1988 Optimization Of Stationary And Moving Beam Radiation-Therapy Techniques Radiother. Oncol. 12 129-140 
Burnside E S, Hall T J, Sommer AM, Hesley G K, Sisney G A, Svensson W E, Fine J P, Jiang J J and Hangiandreou N J 2007 Differentiating benign from malignant solid breast masses with US strain imaging Radiology 245 401-410

Cassell K J, Hobday P A and Parker R P 1981 The implementation of a generalized batho inhomogeneity correction for radiotherapy planning with direct use of CT numbers Phys. Med. Biol. 26 825-833

Castellano I A 2006 Optimisation of Radiation Dose to Patients in Computed tomography, PhD thesis, University of London, London, UK

Cha S, Knopp E A, Johnson G, Wetzel S G, Litt A W and Zagzag D 2002 Intracranial mass lesions: Dynamic contrast-enhanced susceptibility-weighted echo-planar perfusion MR imaging Radiology 223 11-29

Chandra A, Dong L, Huang E, Kuban DA, O'Neill L, Rosen I, Pollack A 2003 Experience of ultrasound-based daily prostate localization Int. J. Radiat. Oncol. Biol. Phys. 56 436-447

Chang C C, Chen MK, Wu H K and Liu M T 2002 Nasopharyngeal carcinoma volume measurements determined with computed tomography: Study of intraobserver and interobserver variability $J$. Otolaryngol. 31 361-365

Chao K S C, Bosch W R, Mutic S, Lewis J S, Dehdashti F, Mintun M A, Dempsey J F, Perez C A, Purdy JA and Welch M J 2001 A novel approach to overcome hypoxic tumor resistance: $\mathrm{Cu}-$ ATSM-guided intensity-modulated radiation therapy Int. J. Radiat. Oncol. Biol. Phys. 49 1171-1182

Chen G T Y, Singh R P, Castro Jr, Lyman J T and Quivey J M 1979 Treatment planning for heavy-ion radiotherapy Int. J. Radiat. Oncol. Biol. Phys. 5 1809-1819

Chen J, Lee R J, Handrahan D and Sause W T 2007 Intensity-modulated radiotherapy using implanted fiducial markers with daily portal imaging: Assessment of prostate organ motion Int. J. Radiat. Oncol. Biol. Phys. 68 912-919

Chen Q S, Weinhous M S, Deibel F C, Ciezki J P and Macklis R M 2001 Fluoroscopic study of tumor motion due to breathing: Facilitating precise radiation therapy for lung cancer patients Med. Phys. 28 1850-1856

Chenevert T L, Stegman L D, Taylor J M G, Robertson P L, Greenberg H S, Rehemtulla A and Ross B D 2000 Diffusion magnetic resonance imaging: an early surrogate marker of therapeutic efficacy in brain tumors J. Natl. Cancer Inst. 92 2029-2036

Cheung P C F, Sixel K E, Tirona R and Ung Y C 2003 Reproducibility of lung tumor position and reduction of lung mass within the planning target volume using active breathing control (ABC) Int. J. Radiat. Oncol. Biol. Phys. 57 1437-1442

Choi Y M, Kim J K, Lee H S, Hur W J, Hong Y S, Park S, Ahn K and Cho H L 2006 Influence of intravenous contrast agent on dose calculations of intensity modulated radiation therapy plans for head and neck cancer Radiother. Oncol. 81 158-162

Christensen G E, Carlson B, Chao K S C, Yin P, Grigsby P W, Nguyen K, Dempsey J F, Lerma F A, Bae KT, Vannier M W and Williamson J F 2001 Image-based dose planning of intracavitary brachytherapy: Registration of serial-imaging studies using deformable anatomic templates Int. J. Radiat. Oncol. Biol. Phys. 51 227-243

Coles C E, Cash C J C, Treece G M, Miller F N A C, Hoole A C F, Gee A H, Prager R W, Sinnatamby R, Britton P, Wilkinson J S, Purushotham AD and Burnet N G 2007 High definition threedimensional ultrasound to localise the tumour bed: A breast radiotherapy planning study Radiother. Oncol. 84 233-241

Coolens C and Childs P J 2003 Calibration of CT Hounsfield units for radiotherapy treatment planning of patients with metallic hip prostheses: the use of the extended CT-scale Phys. Med. Biol. 48 1591-1603

Coolens C, Evans P M, Seco J, Webb S, Blackall J M, Rietzel E and Chen G T Y 2006 The susceptibility of IMRT dose distributions to intrafraction organ motion: An investigation into smoothing filters derived from four dimensional computed tomography data Med. Phys. 33 2809-2818

Court L, Rosen I, Mohan R and Dong L 2003 Evaluation of mechanical precision and alignment uncertainties for an integrated CT/LINAC system Med. Phys. 30 1198-1210

Creutzberg C L, Althof V G M, Huizenga H, Visser A G and Levendag P C 1993 Quality assurance using portal imaging - the accuracy of patient positioning in irradiation of breast-cancer Int. J. Radiat. Oncol. Biol. Phys. 25 529-539

Crook J M, Raymond Y, Salhani D, Yang H and Esche B 1995 Prostate motion during standard radiotherapy as assessed by fiducial markers Radiother. Oncol. 37 35-42 
Cury F L B, Shenouda G, Souhami L, Duclos M, Faria S L, David M, Verhaegen F, Corns R and Falco T 2006 Ultrasound-based image guided radiotherapy for prostate cancer - Comparison of cross-modality and intramodality methods for daily localization during external beam radiotherapy Int. J. Radiat. Oncol. Biol. Phys. 66 1562-1567

Dawson L A, Brock K K, Kazanjian S, Fitch D, McGinn C J, Lawrence T S, Ten Haken R K and Balter J 2001 The reproducibility of organ position using active breathing control (ABC) during liver radiotherapy Int. J. Radiat. Oncol. Biol. Phys. 51 1410-1421

De Boer J C J, Heijmen B J M, Pasma K L and Visser AG 2000 Characterization of a high-elbow, fluoroscopic electronic portal imaging device for portal dosimetry Phys. Med. Biol. 45 197216

De Boer H C J and Heijmen B J M 2001 A protocol for the reduction of systematic patient setup errors with minimal portal imaging workload Int. J. Radiat. Oncol. Biol. Phys. 50 1350-1365

De Boer H C J and Heijmen B J M 2007 eNAL: An extension of the NAL setup correction protocol for effective use of weekly follow-up measurements Int. J. Radiat. Oncol. Biol. Phys. $671586-$ 1595

DeBiose D A, Horwitz E M, Martinez A A, Edmundson G K, Chen P Y, Gustafson G S, Madrazo B, Wimbish K, Mele E and Vicini FA 1997 The use of ultrasonography in the localization of the lumpectomy cavity for interstitial brachytherapy of the breast Int. J. Radiat. Oncol. Biol. Phys. 38 755-759

Debois M, Oyen R, Maes F, Verswijvel G, Gatti G, Bosmans H, Feron M, Bellon E, Kutcher G, Van Poppel H, and Vanuytsel L 1999 The contribution of magnetic resonance imaging to the threedimensional treatment planning of localized prostate cancer Int. J. Radiat. Oncol. Biol. Phys. 45 857-865

Deneve W, Vandenheuvel F, Debeukeleer M, Coghe M, Thon L, Deroover P, Vanlancker M and Storme G 1992 Routine clinical online portal imaging followed by immediate field adjustment using a tele-controlled patient couch Radiother. Oncol. 24 45-54

Ding G X, Duggan D M and Coffey C W 2007 Characteristics of kilovoltage x-ray beams used for cone-beam computed tomography in radiation therapy Phys. Med. Biol. 52 1595-1615

Elgayed Aah, Bel A, Vijlbrief R, Bartelink H and Lebesque Jv 1993 Time trend of patient setup deviations during pelvic irradiation using electronic portal imaging Radiother. Oncol. 26 162171

Endo M, Tsunoo T, Nakamori N and Yoshida K 2001 Effect of scattered radiation on image noise in cone beam CT Med. Phys. 28 469-474

Evans P M, Coolens C and Nioutsikou E 2006a Effects of averaging over motion and the resulting systematic errors in radiation therapy Phys. Med. Biol. 51 N1-N7

Evans P M, Mosleh-Shirazi M A, Harris E J and Seco J 2006b Monte Carlo and Lambertian light guide models of the light output from scintillation crystals at megavoltage energies Med. Phys. 33 1797-1809

Ezz A, Munro P, Porter A T, Battista J, Jaffray Da, Fenster A and Osborne S 1992 Daily monitoring and correction of radiation-field placement using a video-based portal imaging-system - a pilot-study Int. J. Radiat. Oncol. Biol. Phys. 22 159-165

Featherstone C, Harnett A N, Brunt A M 1999 Ultrasound localization of the ovaries for radiationinduced ovarian ablation Clin. Oncol. 11 393-397

Feldkamp L A, Davis L C and Kress J W 1984 Practical cone-beam algorithm J. Opt. Soc. Am. A-Opt. Image Sci. 1 612-619

Fiorino C, Reni M, Bolognesi A, Cattaneo GM and Calandrino R 1998 Intra- and inter-observer variability in contouring prostate and seminal vesicles: implications for conformal treatment planning Radiother. Oncol. 47 285-292

Ford E C, Mageras G S, Yorke E, Rosenzweig K E, Wagman R and Ling C C 2002a Evaluation of respiratory movement during gated radiotherapy using film and electronic portal imaging Int. J. Radiat. Oncol. Biol. Phys. 52 522-531

Ford E C, Chang J, Mueller K, Sidhu K, Todor D, Mageras G, Yorke E, Ling C C and Amols H 2002b Cone-beam CT with megavoltage beams and an amorphous silicon electronic portal imaging device: Potential for verification of radiotherapy of lung cancer Med. Phys. 29 2913-2924

Forrest L J, Mackie T R, Ruchala K, Turek M, Kapatoes J, Jaradat H, Hui S, Balog J, Vail D M and Mehta M P 2004 The utility of megavoltage computed tomography images from a helical tomotherapy system for set-up verification purposes Int. J. Radiat. Oncol. Biol. Phys. 60 16391644

Fowler J, Rick Chappell R and Ritter M 2001 Is $\alpha / \beta$ for prostate tumors really low? Int. J Radiat. Oncol. Biol. Phys. 50 1021-31 
Fransson P, Bergstrom P, Lofroth P O and Widmark A 2002 Prospective evaluation of urinary and intestinal side effects after BeamCath ${ }^{\circledR}$ stereotactic dose-escalated radiotherapy of prostate cancer Radiother. Oncol. 63 239-248

Gierga D P, Brewer J, Sharp G C, Betke M, Willett C G and Chen G T Y 2005 The correlation between internal and external markers for abdominal tumors: Implications for respiratory gating Int. J. Radiat. Oncol. Biol. Phys. 61 1551-1558

Gildersleve J, Dearnaley D P, Evans P M, Law M, Rawlings C and Swindell W 1994 A randomized trial of patient repositioning during radiotherapy using a megavoltage imaging-system Radiother. Oncol. 31 161-168

Gill S S, Thomas D G T, Warrington A P and Brada M 1991 Relocatable frame for stereotaxic external beam radiotherapy Int. J. Radiat. Oncol. Biol. Phys. 20 599-603

Greer PB 2005 Correction of pixel sensitivity variation and off-axis response for amorphous silicon EPID dosimetry Med. Phys. 32 3558-3568

Grosu A L, Piert M, Weber W A, Jeremic B, Picchio M, Schratzenstaller U, Zimmermann FB, Schwaiger M and Molls M 2005 Positron emission tomography for radiation treatment planning Strahlentherapie und Onkologie 181 483-499

Grosu A L and Bortfeld T 2008 Biological imaging Phys. Med. Biol. (in press).

Gustafsson A, Lind B K and Brahme A 1994 A generalized pencil beam algorithm for optimization of radiation-therapy Med. Phys. 21 343-357

Hakime A, Peddi H, Hines-Peralta AU, Wilcox C J, Kruskal J, Lin S Z, de Baere T, Raptopoulos V D and Goldberg S N 2007 CT perfusion for determination of pharmacologically mediated blood flow changes in an animal tumor model Radiology 243 712-719

Hamilton CS, Ebert MA 2005 Volumetric uncertainty in radiotherapy Clin. Oncol. 17 456-464

Hanley J, Debois M M, Mah D, Mageras G S, Raben A, Rosenzweig K, Mychalczak B, Schwartz L H, Gloeggler P J, Lutz W, Ling C C, Leibel S A, Fuks Z and Kutcher G J 1999 Deep inspiration breath-hold technique for lung tumors: The potential value of target immobilization and reduced lung density in dose escalation Int. J. Radiat. Oncol. Biol. Phys. 45 603-611

Hansen V N, Evans P M and Swindell W 1996 The application of transit dosimetry to precision radiotherapy Med. Phys. 23 713-721

Hartkens T, Rohr K and Stiehl H S 2002 Evaluation of 3D operators for the detection of anatomical point landmarks in MR and CT images Comput. Vis. Image Underst. 86 118-136

Hector C L, Webb S and Evans P M 2000 The dosimetric consequences of inter-fractional patient movement on conventional and intensity-modulated breast radiotherapy treatments Radiother. Oncol. 54 57-64

Helyer S J, Moskovic E, Ashley S, Hastings L and Yarnold J R 1999 A study testing the routine use of ultrasound measurements when selecting the electron energy for breast boost radiotherapy Clin. Oncol. 11 164-168

Henry A M, Stratford J, McCarthy C, Davies J, Sykes J R, Amer A, Marchant T, Cowan R, Wylie J, Logue J, Livsey J, Khoo V S, Moore C and Price P 2006 X-ray volume imaging in bladder radiotherapy verification Int. J. Radiat. Oncol. Biol. Phys. 64 1174-1178

Henson P W and Fox R A 1984 The electron-density of bone for inhomogeneity correction in radiotherapy planning using CT numbers Phys. Med. Biol. 29 351-359

Herman M G, Balter J M, Jaffray D A, McGee K P, Munro P, Shalev S, Van Herk M and Wong J W 2001 Clinical use of electronic portal imaging: Report of AAPM radiation therapy committee Task Group 58 Med. Phys. 28 712-737

Herman M G 2005 Clinical use of electronic portal imaging Semin. Radiat. Oncol. 15 157-167

Hermans R, Lambin P, Van der Goten A, Van den Bogaert W, Verbist B, Weltens C, Delaere P R 1999 Tumoural perfusion as measured by dynamic computed tomography in head and neck carcinoma Radiother. Oncol. 53 105-111

Hermans R, Meijerink M, Van den Bogaert W, Rijnders A, Weltens C, Lambin P 2003 Tumor perfusion rate determined noninvasively by dynamic computed tomography predicts outcome in head-and-neck cancer after radiotherapy Int. J. Radiat. Oncol. Biol. Phys. 57 1351-1356

Hesse BM, Spies L and Groh BA 1998 Tomotherapeutic portal imaging for radiation treatment verification Phys. Med. Biol. 43 3607-3616

Hill D L G, Batchelor P G, Holden M and Hawkes D J 2001 Medical image registration Phys. Med. Biol. 46 R1-R45

Hoskin P J and Bownes P 2006 Innovative technologies in radiation therapy: Brachytherapy Semin. Radiat. Oncol. 16 209-217

Hounsfield G N 1973 Computerized transverse axial scanning (tomography) .1. Description of system Br. J. Radiol. 46 1016-1022 
Hsu A, Miller N R, Evans P M, Bamber J C and Webb S 2005 Feasibility of using ultrasound for realtime tracking during radiotherapy Med. Phys. 32 1500-1512

$\mathrm{Hu}$ N, Downey D B, Fenster A and Ladak H M 2003 Prostate boundary segmentation from 3D ultrasound images Med. Phys. 30 1648-1659

Huang E, Dong L, Chandra A, Kuban D A, Rosen I I, Evans A and Pollack A 2002 Intrafraction prostate motion during IMRT for prostate cancer Int. J. Radiat. Oncol. Biol. Phys. 53 261-268

Hurkmans C W, Remeijer P, Lebesque J V and Mijnheer B J 2001 Set-up verification using portal imaging; review of current clinical practice Radiother. Oncol. 58 105-120

International Commission on Radiation Units and Measurement. ICRU Report 501993 Prescribing, recording and reporting photon beam therapy. Bethesda, MD, USA:

International Commission on Radiation Units and Measurement. ICRU Report 621999 Prescribing, recording and reporting photon beam therapy (supplement to ICRU Report 50). Bethesda, MD, USA

Islam M K, Purdie T G Norrlinger B D, Alasti H, Moseley D J, Sharpe M B, Siewerdsen JH and Jaffray D A 2006 Patient dose from kilovoltage cone beam computed tomography imaging in radiation therapy Med. Phys. 33 1573-1582

Jackson A S N, Reinsberg S A, Sohaib S A, Charles-Edwards E M, Mangar S A, South C P, Leach M O and Dearnaley D P 2007 Distortion-corrected T2 weighted MRI: a novel approach to prostate radiotherapy planning Br J Radiol 80: 926-933.

Jaffray D A, Chawla K, Yu C and Wong J W 1995 Dual-beam imaging for online verification of radiotherapy field placement Int. J. Radiat. Oncol. Biol. Phys. 33 1273-1280

Jaffray D A, Drake D G, Moreau M, Martinez A A and Wong J W 1999 A radiographic and tomographic imaging system integrated into a medical linear accelerator for localization of bone and soft-tissue targets Int. J. Radiat. Oncol. Biol. Phys. 45 773-789

Jaffray DA and Siewerdsen J H 2000 Cone-beam computed tomography with a flat-panel imager: Initial performance characterization Med. Phys. 27 1311-1323

Jaffray D A, Siewerdsen J H, Wong J W and Martinez A A 2002 Flat-panel cone-beam computed tomography for image-guided radiation therapy Int. J. Radiat. Oncol. Biol. Phys. 53 13371349

Jaffray DA 2005 Emergent technologies for 3-dimensional image-guided radiation delivery Semin. Radiat. Oncol. 15 208-216

Jaffray D A 2007 Image-guided radiation therapy: From concept to practice Semin. Radiat. Oncol. 17 243-244

Jarry G, Graham S A, Moseley D J, Jaffray D J, Siewerdsen J H and Verhaegen F 2006 Characterization of scattered radiation in $\mathrm{kV}$ CBCT images using Monte Carlo simulations Med. Phys. 33 4320-4329

Jiang S B 2006 Radiotherapy of mobile tumors Semin. Radiat. Oncol. 16 239-248

Jin J Y, Ajlouni M, Ryu S, Chen Q, Li S D and Movsas B 2007 A technique of quantitatively monitoring both respiratory and nonrespiratory motion in patients using external body markers Med. Phys. 34 2875-2881

Kalender W A, Seissler W and Vock P 1989 Single-breath-hold spiral volumetric CT by continuous patient translation and scanning rotation Radiology 173414.

Kalender W A 2006 X-ray computed tomography Phys. Med. Biol. 51 R29-R43

Kanoulas E, Aslam J A, Sharp G C, Berbeco R I, Nishioka S, Shirato H and Jiang S B 2007 Derivation of the tumor position from external respiratory surrogates with periodical updating of the internal/external correlation Phys. Med. Biol. 52 5443-5456

Kapatoes J M, Olivera G H, Balog J P, Keller H, Reckwerdt P J and Mackie T R 2001 On the accuracy and effectiveness of dose reconstruction for tomotherapy Phys. Med. Biol. 46 943-966

Keall P 2004a 4-dimensional computed tomography imaging and treatment planning Semin. Radiat. Oncol. 14 81-90

Keall P J, Starkschall G, Shukla H, Forster K M, Ortiz V, Stevens C W, Vedam S S, George R, Guerrero T and Mohan R 2004b Acquiring 4D thoracic CT scans using a multislice helical method Phys. Med. Biol. 49 2053-2067

Keston P, Murray A D and Jackson A 2003 Cerebral perfusion imaging using contrast-enhanced MRI Clin. Radiol. 58 505-513

Khoo VS, Adams EJ, Saran F, Bedford JL, Perks JR, Warrington AP and Brada M 2000 A comparison of clinical target volumes determined by CT and MRI for the radiotherapy planning of base of skull meningiomas Int. J. Radiat. Oncol. Biol. Phys. 46 1309-1317

Khoo V S and Joon D L 2006 New developments in Mill for target volume delineation in radiotherapy Br. J. Radiol 79 S2-S15 
Kijewski P K and Bjarngard B E 1978 Use of computed tomography data for radiotherapy dose calculations Int. J. Radiat. Oncol. Biol. Phys. 4 429-435

Kirby M C and Glendinning A G 2006 Developments in electronic portal imaging systems $\mathrm{Br}$. $J$. Radiol. 79 S50-S65

Kolen A F, Miller N R, Ahmed E E and Bamber J C 2004 Characterization of cardiovascular liver motion for the eventual application of elasticity imaging to the liver in vivo Phys. Med. Biol. 49 4187-4206

Kooy H M, Vanherk M, Barnes P D, Alexander E, Dunbar S F, Tarbell N J, Mulkern R V, Holupka E J and Loeffler J S 1994 Image fusion for stereotaxic radiotherapy and radiosurgery treatment planning Int. J. Radiat. Oncol. Biol. Phys. 28 1229-1234

Kubo H D and Hill B C 1996 Respiration gated radiotherapy treatment: A technical study Phys. Med. Biol. 41 83-91

Kupelian P, Willoughby T, Mahadevan A, Djemil T, Weinstein G, Jani S, Enke C, Solberg T, Flores N, Liu D, Beyer D and Levine L 2007 Multi-institutional clinical experience with the Calypso System in localization and continuous, real-time monitoring of the prostate gland during external radiotherapy Int. J. Radiat. Oncol. Biol. Phys. 67 1088-1098

Kuriyama K, Onishi H, Sano N, Komiyama T, Aikawa Y, Tateda Y, Araki T and Uematsu M 2003 A new irradiation unit constructed of self-moving gantry-CT and linac Int. J. Radiat. Oncol. Biol. Phys. 55 428-435

Lagerwaard F J, de Koste J R V, Nijssen-Visser M R J, Schuchhard-Schipper R H, Oei S S, Munne A and Senan S 2001 Multiple "slow" CT scans for incorporating lung tumor mobility in radiotherapy planning Int. J. Radiat. Oncol. Biol. Phys. 51 932-937

Land I, Mills J A, Young K, Haas O, Wilson A and Burnham K J 2007 Modelling target coverage for respiratory-gated radiotherapy with simulated and real breathing traces Strahlentherapie und Onkologie 183 19-20

Langen K M, Pouliot J, Anezinos C, Aubin M, Gottschalk A R, Hsu I C, Lowther D, Liu Y M, Shinohara K, Verhey L J, Weinberg V and Roach M 2003 Evaluation of ultrasound-based prostate localization for image-guided radiotherapy Int. J. Radiat. Oncol. Biol. Phys. 57 635644

Langen K M, Meeks S L, Poole D O, Wagner T H, Willoughby T R, Kupelian P A, Ruchala K J, Haimerl J and Olivera G H 2005 The use of Megavoltage CT (MVCT) images for dose recomputations Phys. Med. Biol. 50 4259-4276

Langmack K A 2001 Portal imaging Br. J. Radiol. 74 789-804

Lawton C A., DeSilvio M, Lee W R, Gomella L, Grignon D, Gillin M, Morton G, Pisansky T and Sandler H 2007 Results of a phase II trial of transrectal ultrasound-guided permanent radioactive implantation of the prostate for definitive management of localized adenocarcinoma of the prostate (Radiation Therapy Oncology Group 98-05) Int. J. Radiation Oncology Biol. Phys. 67 39-47.

Lee Y K, Bollet M, Charles-Edwards G, Flower M A, Leach M O, McNair H, Moore E, Rowbottom C and Webb S 2003 Radiotherapy treatment planning of prostate cancer using magnetic resonance imaging alone Radiother. Oncol. 66 203-216

Létourneau D, Wong J W, Oldham M, Gulam M, Watt L, Jaffray D A, Siewerdsen J H and Martinez AA 2005 Cone-beam-CT guided radiation therapy: technical implementation Radiother. Oncol. 75 279-286

Létourneau D, Wong R, Moseley D, Sharpe M B, Ansell S, Gospodarowicz M and Jaffray DA 2007 Online planning and delivery technique for radiotherapy of spinal metastases using cone-beam CT: image quality and system performance Int. J. Radiation Oncology Biol. Phys. 67 12291237

Lewis D G, Swindell W, Morton E J, Evans P M and Xiao Z R 1992 A megavoltage CT Scanner for radiotherapy verification Phys. Med. Biol. 37 1985-1999

Lewis M A 2001 Multislice CT: opportunities and challenges Br. J. Radiol. 74 779-781

Little D J, Dong L, Levy L B, Chandra A and Kuban DA 2003 Use of portal images and bat ultrasonography to measure setup error and organ motion for prostate IMRT: Implications for treatment margins Int. J. Radiat. Oncol. Biol. Phys. 56 1218-1224

Litzenberg D, Dawson LA, Sandler H, Sanda M G, McShan D L, Ten Haken R K, Lam K L, Brock K K and Balter J M 2002 Daily prostate targeting using implanted radiopaque markers Int. J. Rad. Oncol. Biol. Phys. 52 699-703

Litzenberg D W, Willoughby T R, Balter J M, Sandler H M, Wei J, Kupflian P A, Cunningham A A, Bock A, Aubin M, Roach M, Shinohara K and Pouliot J 2007 Positional stability of electro- 
magnetic transponders used for prostate localization and continuous, real-time tracking Int. J. Radiat. Oncol. Biol. Phys. 68 1199-1206

Low D A, Nystrom M, Kalinin E, Parikh P, Dempsey J F, Bradley J D, Mutic S, Wahab S H, Islam T, Christensen G, Politte D G and Whiting B R 2003 A method for the reconstruction of fourdimensional synchronized CT scans acquired during free breathing Med. Phys. 30 1254-1263

Low D, Parikh P, Lu W, Dempsey J, Wahab S, Hubenschmidt J, Nystrom M, Handoko M and Bradley J 2005 Novel breathing motion model for radiotherapy Int. J. Rad. Oncol. Biol. Phys. 63 921929

Lu H M, Cash E, Chen M H, Chin L, Manning W J, Harris J and Bornstein B 2000 Reduction of cardiac volume in left-breast treatment fields by respiratory maneuvers: A CT study Int. J. Radiat. Oncol. Biol. Phys. 47 895-904

Lu W G, Olivera G H, Chen Q, Ruchala K J, Haimerl J, Meeks S L, Langen K M and Kupelian P A 2006a Deformable registration of the planning image (kVCT) and the daily images (MVCT) for adaptive radiation therapy Phys. Med. Biol. 51 4357-4374

Lu W, Parikh P J, Hubenschmidt J P, Bradley J D, Low D A 2006b A comparison between amplitude sorting and phase-angle sorting using external respiratory measurement for 4D CT Med. Phys. 33 2964-2974

Lujan A E, Larsen E W, Balter J M and Ten Haken R K 1999 A method for incorporating organ motion due to breathing into 3D dose calculations Med. Phys. 26 715-720

Ma C M and Paskalev K 2006 In-room CT techniques for image-guided radiation therapy Med. Dosim. 31 30-39

Machtay M, Lanciano R, Hoffman J and Hanks G E 1994 Inaccuracies in using the lumpectomy scar for planning electron boosts in primary breast-carcinoma Int. J. Radiat. Oncol. Biol. Phys. 30 43-48

Mackie T R, Balog J, Ruchala K, Shepard D, Aldridge S, Fitchard E, Reckwerdt P, Olivera G, McNutt T and Mehta M 1999 Tomotherapy Semin. Radiat. Oncol. 9 108-117

Mageras G S and Yorke E 2004 Deep inspiration breath hold and respiratory gating strategies for reducing organ motion in radiation treatment Semin. Radiat. Oncol. 14 65-75

Malone S, Crook J M, Kendal W S and Szanto J 2000 Respiratory-induced prostate motion: Quantification and characterization Int. J. Radiat. Oncol. Biol. Phys. 48 105-109

Malusek A, Seger M M, Sandborg M and Carlsson G A 2005 Effect of scatter on reconstructed image quality in cone beam computed tomography: Evaluation of a scatter-reduction optimisation function Radiat. Prot. Dosim. 114 337-340

Mansfield P 2004 Snapshot magnetic resonance imaging (Nobel lecture) Angewandte ChemieInternational 43 5456-5464

Marks L B, Hebert M E, Bentel G, Spencer D P, Sherouse G W and Prosnitz L R 1994 To treat or not to treat the internal mammary nodes - a possible compromise Int. J. Radiat. Oncol. Biol. Phys. 29 903-909

Marmulla R, Luth T, Muhling J and Hassfeld S 2004 Markerless laser registration in image-guided oral and maxillofacial surgery J. Oral Maxillofac. surg. 62 845-851

Martinez A A, Yan D, Lockman D, Brabbins D, Kota K, Sharpe M, Jaffray D A, Vicini F and Wong J 2001 Improvement in dose escalation using the process of adaptive radiotherapy combined with three-dimensional conformal or intensity-modulated beams for prostate cancer Int. J. Radiat. Oncol. Biol. Phys. 50 1226-1234

McClelland J R, Webb S, McQuaid D, Binnie D M, Hawkes D J 2007 Tracking 'differential organ motion' with a 'breathing' multileaf collimator: magnitude of problem assessed using 4D CT data and a motion-compensation strategy Phys. Med. Biol. 52 4805-4826

McCurdy BMC, Luchka K and Pistorius S 2001 Dosimetric investigation and portal dose image prediction using an amorphous silicon electronic portal imaging device Med. Phys. 28 911924

McDermott L N, Louwe R J W, Sonke J J, van Herk M B and Mijnheer B J 2004 Dose-response and ghosting effects of an amorphous silicon electronic portal imaging device Med. Phys. 31 285295

McDermott L N, Wendling M, Sonke J J, van Herk M, Mijnheer B J 2006 Anatomy changes in radiotherapy detected using portal imaging Radiother. Oncol. 79 211-217

McGahan J P, Ryu J and Fogata M 2004 Ultrasound probe pressure as a source of error in prostate localization for external beam radiotherapy Int. J. Radiat. Oncol. Biol. Phys. 60 788-793

McKenzie A L, van Herk M and Mijnheer B 2000 The width of margins in radiotherapy treatment plans Phys. Med. Biol. 45 3331-3342 
McKenzie A L, van Herk M and Mijnheer B 2002 Margins for geometric uncertainty around organs at risk in radiotherapy Radiother. Oncol. 62 299-307

McNutt T R, Mackie T R, Reckwerdt P and Paliwal B R 1996 Modeling dose distributions from portal dose images using the convolution/superposition method Med. Phys. 23 1381-1392

McQuaid D and Webb S 2006 IMRT delivery to a moving target by dynamic MLC tracking: delivery for targets moving in two dimensions in the beam's eye view Phys. Med. Biol. 51 4819-4839

Meeks S L, Harmon J F, Langen K M, Willoughby T R, Wagner T H and Kupelian P A 2005 Performance characterization of megavoltage computed tomography imaging on a helical tomotherapy unit Med. Phys. 32 2673-2681

Merrick G S, Butler W M, Dorsey A T, Lief J H, Walbert H L and Blatt H J 1999 Rectal dosimetric analysis following prostate brachytherapy Int. J. Radiat. Oncol. Biol. Phys. 43 1021-1027

Miles KA, Griffiths MR 2003 Perfusion CT: a worthwhile enhancement? Br. J. Radiol. 76 220-231

Minohara S, Kanai T, Endo M, Noda K, Kanazawa M 2000 Respiratory gated irradiation system for heavy-ion radiotherapy Int. J. Radiat. Oncol. Biol. Phys. 47 1097-1103

Moore C, Lilley F, Sauret V, Lalor M and Burton D 2003 Opto-electronic sensing of body surface topology changes during radiotherapy for rectal cancer Int. J. Radiat. Oncol. Biol. Phys. 56 248-258

Morin O, Chen J, Aubin M, Gillis A, Aubry J F, Bose S, Chen H, Descovich M, Xia P and Pouliot J 2007 Dose calculation using megavoltage cone-beam CT Int. J. Radiat. Oncol. Biol. Phys. 67 1201-1210

Mosleh-Shirazi M A, Evans P M, Swindell W, Symonds-Tayler J R N, Webb S and Partridge M 1998a Rapid portal imaging with a high-efficiency, large field-of-view detector Med. Phys. 252333 2346

Mosleh-Shirazi M A, Evans P M, Swindell W, Webb S and Partridge M 1998b A cone-beam megavoltage CT scanner for treatment verification in conformal radiotherapy Radiother. Oncol. 48 319-328

Mukherji S K, Toledano A Y, Beldon C, Schmalfuss I M, Cooper J S, Sicks J D, Amdur R, Sailer S, Loevner L A, Kousouboris P and Ang K 2005 Interobserver reliability of computed tomography derived primary tumor volume measurement in patients with supraglottic carcinoma Cancer 103 2616-2622

Murphy M J, Chang S D, Gibbs I C, Le Q T, Hai J, Kim D, Martin D P and Adler J R 2003 Patterns of patient movement during frameless image-guided radiosurgery Int. J. Radiat. Oncol. Biol. Phys. 55 1400-1408

Mustafa A A and Jackson D F 1983 The relation between x-ray ct numbers and charged-particle stopping powers and its significance for radiotherapy treatment planning Phys. Med. Biol. 28 169-176

Nabavi D G, Cenic A, Craen R A, Gelb A W, Bennett J D, Kozak R and Lee TY 1999 CT assessment of cerebral perfusion: Experimental validation and initial clinical experience Radiology 213 141-149

Nagakawa K, Aoki Y, Akanuma A, Onogi Y, Karasawa K, Terahara A, Hasezawa K and Sasaki Y, 1991, Development of a megavoltage CT scanner using linear accelerator treatment beam, $J$. Jpn. Soc. Ther. Radiol. Oncol. 3 265-276.

Nalder C A, Bidmead A M, Mubata C D, Tait D and Beardmore C 2001 Influence of a vac-fix immobilization device on the accuracy of patient positioning during routine breast radiotherapy Br. J. Radiol. 74 249-254

Nederveen A J, van der Heide U A, Dehnad H, van Moorselaar R J A, Hofman P, Lagendijk J J W 2002 Measurements and clinical consequences of prostate motion during a radiotherapy fraction Int. J. Radiat. Oncol. Biol. Phys. 53 206-214

Nederveen A J, Dehnad H, van der Heide U A, van Moorselaar R J A, Hofman P, Lagendijk J J W 2003 Comparison of megavoltage position verification for prostate irradiation based on bony anatomy and implanted fiducials Radiother. Oncol. 68 81-88

Newbold K, Sohaib A, Castellano I, Mears D, A'Hern R, Rhys-Evans P, Fisher C, Harrington K and Nutting C 2005 Validation of perfusion computed tomography (CT) parameters as surrogate markers of hypoxia in squamous cell carcinoma of the head and neck EJC Supplements 3400 400

Nishidai T, Nagata Y, Takahashi M, Abe M, Yamaoka N, Ishihara H, Kubo Y, Ohta H and Kazusa C 1990 CT simulator - a new 3-D planning and simulating system for radiotherapy .1. description of system Int. J. Radiat. Oncol. Biol. Phys. 18 499-504

O'Connor J E 1957 The Variation of Scattered X-Rays with Density in an Irradiated Body Phys. Med. Biol. 1 352-369 
Ohara K, Okumura T, Akisada M, Inada T, Mori T, Yokota H and Calaguas M J B 1989 Irradiation synchronized with respiration gate Int. J. Radiat. Oncol. Biol. Phys. 17 853-857

Ohnesorge B, Flohr T, Becker C, Knez A, Kopp A F, Fukuda K and Reiser M F 2000 Cardiac imaging with retrospectively ECG-gated fast multi-slice spiral CT Radiologe 40 111-117

Orecchia R, Jereczek-Fossa BA, Ciocca M, Vavassori A, Cambria R, Cattani F, Zerini D, Matei D V, Rocco B, Verweij F, Scardino E and DeCobelli O 2007 Intraoperative radiotherapy for locally advanced prostate cancer: Treatment technique and ultra sound-based analysis of dose distribution Anticancer Res. 27 3471-3476

Ozhasoglu C and Murphy M J 2002 Issues in respiratory motion compensation during external-beam radiotherapy Int. J. Radiat. Oncol. Biol. Phys. 52 1389-1399

Padhani A R, Khoo V S, Suckling J, Husband J E, Leach MO and Dearnaley DP 1999 Evaluating the effect of rectal distension and rectal movement on prostate gland position using cine MRI Int. J. Radiat. Oncol. Biol. Phys. 44 525-533

Pagoulatos N, Haynor DR and Kim Y 2001 A fast calibration method for 3-D tracking of ultrasound images using a spatial localizer Ultrasound Med. Biol. 27 1219-1229

Pang G and Rowlands J A 2002 Development of high quantum efficiency flat panel detectors for portal imaging: Intrinsic spatial resolution Med. Phys. 29 2274-2285

Parent L, Seco J, Evans P M, Fielding A and Dance D R 2006 Monte Carlo modelling of a-Si EPID response: The effect of spectral variations with field size and position Med. Phys. 33 45274540

Parker R P, Hobday P A and Cassell K J 1979 Direct use of CT numbers in radiotherapy dosage calculations for inhomogeneous-media Phys. Med. Biol. 24 802-809

Pasma K L, Kroonwijk M, Quint S, Visser A G and Heijmen B J M 1999 Transit dosimetry with an electronic portal imaging device (EPID) for 115 prostate cancer patients Int. J. Radiat. Oncol. Biol. Phys. 45 1297-1303

Payne G S and Leach M O 2006 Applications of magnetic resonance spectroscopy in radiotherapy treatment planning Br. J. Radiol. 79 S16-S26

Peignaux K, Truc G, Barillot I, Ammor A, Naudy S, Crehange G and Maingon P 2006 Clinical assessment of the use of the Sonarray system for daily prostate localization Radiother. Oncol. 81 176-178

Petersch B, Bogner J, Fransson A, Lorang T and Potter R 2004 Effects of geometric distortion in 0.2 T MRI on radiotherapy treatment planning of prostate cancer Radiother. Oncol. 71 55-64

Pisani L, Lockman D, Jaffray D, Yan D, Martinez A, Wong J 2000 Setup error in radiotherapy: On-line correction using electronic kilovoltage and megavoltage radiographs Int. J. Radiat. Oncol. Biol. Phys. 47 825-839

Ploeger L S, Frenay M, Betgen A, de Bois JA, Gilhuijs K G A and van Herk M 2003 Application of video imaging for improvement of patient set-up Radiother. Oncol. 68 277-284

Poggi M M, Gant D A, Sewchand W and Warlick W B 2003 Marker seed migration in prostate localization Int. J. Radiat. Oncol. Biol. Phys. 56 1248-1251

Pos F J, Hulshof M, Lebesque J, Lotz H, van Tienhoven G R, Moonen L and Remeijer P 2006 Adaptive radiotherapy for invasive bladder cancer: A feasibility study Int. J. Radiat. Oncol. Biol. Phys. 64 862-868

Pouliot J, Bani-Hashemi A, Chen J, Svatos M, Ghelmansarai F, Mitschke M, Aubin M, Xia P, Morin O, Bucci K, Roach M, Hernandez P, Zheng Z R, Hristov D and Verhey L 2005 Low-dose megavoltage cone-beam CT for radiation therapy Int. J. Radiat. Oncol. Biol. Phys. 61 552-560

Pouliot J, Sonke J, Tome W, Lagendijk J, Brock K, Kessler M and Siewerdsen J 2007 The great debate: The future of IGRT is ... Megavolt CT ... Kilovoltage CT ... Ultrasound-based hybrids ... MRI guidance ... 3D deformable image registration Med. Phys. 34 2556-2557

Prager R, Gee A, Treece G and Berman L 2002 Freehand 3D ultrasound without voxels: volume measurement and visualisation using the Stradx system Ultrasonics 40 109-115

Prott F J, Haverkamp U, Eich H, Resch A, Micke O, Fischedick A R, Willich N and Potter R 2000 Effect of distortions and asymmetry in MR images on radiotherapeutic treatment planning Int. J. Cancer 90 46-50

Raaymakers B W, Raaijmakers A J E, Kotte A N T J, Jette D and Lagendijk J J W 2004 Integrating a MRI scanner with a $6 \mathrm{MV}$ radiotherapy accelerator: dose deposition in a transverse magnetic field Phys. Med. Biol. 49 4109-4118

Rasch C, Barillot I, Remeijer P, Touw A, van Herk M and Lebesque J V 1999 Definition of the prostate in CT and MRI: A multi-observer study Int. J. Radiat. Oncol. Biol. Phys. 43 57-66

Remouchamps V M, Vicini F A, Sharpe M B, Kestin L L, Martinez A A and Wong J W 2003 Significant reductions in heart and lung doses using deep inspiration breath hold with active 
breathing control and intensity-modulated radiation therapy for patients treated with locoregional breast irradiation Int. J. Radiat. Oncol. Biol. Phys. 55 392-406

Reynaert N, Van Eijkeren M, Taeymans Y, Thierens H 2001 Dosimetry of Ir-192 sources used for endovascular brachytherapy Phys. Med. Biol. 46 499-516

Reynaert N, van der Marck S C, Schaart D R, Van der Zee W, Van Vliet-Vroegindeweij C, Tomsej M, Jansen J, Heijmen B, Coghe M and De Wagter C 2007 Monte Carlo treatment planning for photon and electron beams Radiat. Phys. Chem. 76 643-686

Rietzel E, Chen G T Y, Choi N C and Willet C G 2005a Four-dimensional image-based treatment planning: Target volume segmentation and dose calculation in the presence of respiratory motion Int. J. Radiat. Oncol. Biol. Phys. 61 1535-1550

Rietzel E, Pan T S and Chen G T Y 2005b Four-dimensional computed tomography: Image formation and clinical protocol Med. Phys. 32 874-889

Rietzel E, Liu A K, Doppke K P, Wolfgang J A, Chen A B, Chen G T Y and Choi N C 2006 Design of 4D treatment planning target volumes Int. J. Radiat. Oncol. Biol. Phys. 66 287-295

Roach M, Pickett B, Holland J, Zapotowski K A, Marsh D L and Tatera B S 1993 The role of the urethrogram during simulation for localized prostate-cancer Int. J. Radiat. Oncol. Biol. Phys. 25 299-307

Roach M, FaillaceAkazawa P, Malfatti C, Holland J and Hricak H 1996 Prostate volumes defined by magnetic resonance imaging and computerized tomographic scans for three-dimensional conformal radiotherapy Int. J. Radiat. Oncol. Biol. Phys. 35 1011-1018

Rouviere O, Valette O, Grivolat S, Colin-Pangaud C, Bouvier R, Chapelon Y, Gelet A and Lyonnet D 2004 Recurrent prostate cancer after external beam radiotherapy: Value of contrast-enhanced dynamic MRI in localizing intraprostatic tumor correlation with biopsy findings Urology 63 922-927

Ruchala K J, Olivera G H, Schloesser E A and Mackie T R 1999 Megavoltage CT on a tomotherapy system Phys. Med. Biol. 44 2597-2621

Rueckert D, Sonoda L I, Hayes C, Hill D L G, Leach M O and Hawkes D J 1999 Nonrigid registration using free-form deformations: Application to breast MR images IEEE Trans. Med. Imaging 18 712-721

Sahinler I, Cepni I, Oksuz DC, Cepni K, Koksal S, Koca A, Atkovar G and Okkan S 2004 Tandem application with transvaginal ultrasound guidance Int. J. Radiat. Oncol. Biol. Phys. 59 190196

Sawada A, Yoda K, Kokubo M, Kunieda T, Nagata Y and Hiraoka M 2004 A technique for noninvasive respiratory gated radiation treatment system based on a real time 3D ultrasound image correlation: A phantom study Med. Phys. 31 245-250

Sawant A, Zeman H, Samant S, Lovhoiden G, Weinberg B and DiBianca F 2002 Theoretical analysis and experimental evaluation of a $\mathrm{CsI}(\mathrm{Tl})$ based electronic portal imaging system Med. Phys. 29 1042-1053

Sawant A, Antonuk L E, El-Mohri Y, Li YX, Su Z, Wang Y, Yamamoto J, Zhao QH, Du H, Daniel J and Street R 2005 Segmented phosphors; MEMS-based high quantum efficiency detectors for megavoltage x-ray imaging Med. Phys. 32 553-565

Schneider U, Pedroni E, Lomax A 1996 The calibration of CT Hounsfield units for radiotherapy treatment planning Phys. Med. Biol. 41 111-124

Schoffel P J, Harms W, Sroka-Perez G, Schlegel W and Karger C P 2007 Accuracy of a commercial optical 3D surface imaging system for realignment of patients for radiotherapy of the thorax Phys. Med. Biol. 52 3949-3963

Schreibmann E, Chen G T Y and Xing L 2006 Image interpolation in 4D CT using a BSpline deformable registration model Int. J. Radiat. Oncol. Biol. Phys. 64 1537-1550

Seco J, Evans PM 2006 Assessing the effect of electron density in photon dose calculations Med. Phys. 33 540-552

Seco J, Sharp G C, Turcotte J, Gierga D, Bortfeld T and Paganetti H 2007 Effects of organ motion on IMRT treatments with segments of few monitor units Med. Phys. 34 923-934

Seppenwoolde Y, Shirato H, Kitamura K, Shimizu S, van Herk M, Lebesque JV and Miyasaka K 2002 Precise and real-time measurement of 3D tumor motion in lung due to breathing and heartbeat, measured during radiotherapy Int. J. Radiat. Oncol. Biol. Phys. 53 822-834

Seppenwoolde Y, Berbeco R I, Nishioka S, Shirato H, Heijmen B 2007 Accuracy of tumor motion compensation algorithm from a robotic respiratory tracking system: A simulation study Med. Phys. 34 2774-2784 
Seppi E J, Munro P, Johnsen S W, Shapiro E G, Tognina C, Jones D, Pavkovich J M, Webb C, Mollov I, Partain L D and Colbeth R E 2003 Megavoltage cone-beam computed tomography using a high-efficiency image receptor Int. J. Radiat. Oncol. Biol. Phys. 55 793-803

Shen S, Duan J, Fiveash J B, Brezovich I A, Plant B A, Spencer S A, Popple R A, Pareek P N and Bonner J A 2003 Validation of target volume and position in respiratory gated CT planning and treatment Med. Phys. 30 3196-3205

Sherouse G W, Novins K and Chaney E L 1990 Computation of digitally reconstructed radiographs for use in radiotherapy treatment design Int. J. Radiat. Oncol. Biol. Phys. 18 651-658

Shimizu S, Shirato H, Ogura S, Akita-Dosaka H, Kitamura K, Nishioka T, Kagei K, Nishimura M and Miyasaka K 2001 Detection of lung tumor movement in real-time tumor-tracking radiotherapy Int. J. Radiat. Oncol. Biol. Phys. 51 304-310

Shirato H, Shimizu S, Kitamura K, Nishioka T, Kagei K, Hashimoto S, Aoyama H, Kunieda T, Shinohara N, Dosaka-Akita H and Miyasaka K 2000a Four-dimensional treatment planning and fluoroscopic real-time tumor tracking radiotherapy for moving tumor Int. J. Radiat. Oncol. Biol. Phys. 48 435-442

Shirato H, Shimizu S, Kunieda T, Kitamura K, van Herk M, Kagei K, Nishioka T, Hashimoto S, Fujita K, Aoyama H, Tsuchiya K, Kudo K and Miyasaka K 2000b Physical aspects of a real-time tumor-tracking system for gated radiotherapy Int. J. Radiat. Oncol. Biol. Phys. 48 1187-1195

Shirato H, Oita M, Fujita K, Watanabe Y and Miyasaka K 2004a Feasibility of synchronization of realtime tumor-tracking radiotherapy and intensity-modulated radiotherapy from viewpoint of excessive dose from fluoroscopy Int. J. Radiat. Oncol. Biol. Phys. 60 335-341

Shirato H, Seppenwoolde Y, Kitamura K, Onimura R and Shimizu S 2004b Intrafractional tumor motion: Lung and liver Semin. Radiat. Oncol. 14 10-18

Shirato H, Suzuki K, Sharp G C, Fujita K, Onimaru R, Fujino M, Kato N, Osaka Y, Kinoshita R, Taguchi H, Onodera S and Miyasaka K 2006 Speed and amplitude of lung tumor motion precisely detected in four-dimensional setup and in real-time tumor-tracking radiotherapy Int. J. Radiat. Oncol. Biol. Phys. 64 1229-1236

Sidhu K, Ford E C, Spirou S, Yorke E, Chang J W, Mueller K, Todor D, Rosenzweig K, Mageras G, Chui C, Ling C C and Amols H 2003 Optimization of conformal thoracic radiotherapy using cone-beam CT imaging for treatment verification Int. J. Radiat. Oncol. Biol. Phys. 55 757-767

Sidhu K, Cooper P, Ramani R, Schwartz M, Franssen E and Davey P 2004 Delineation of brain metastases on CT images for planning radiosurgery: concerns regarding accuracy $\mathrm{Br}$. $J$. Radiol. 77 39-42

Siebers J V, Kim J O, Ko L, Keall P J and Mohan R 2004 Monte Carlo computation of dosimetric amorphous silicon electronic portal images Med. Phys. 31 2135-2146

Siewerdsen J H and Jaffray D A 2001 Cone-beam computed tomography with a flat-panel imager: Magnitude and effects of x-ray scatter Med. Phys. 28 220-231

Siewerdsen J H, Moseley D J, Bakhtiar B, Richard S and Jaffray D A 2004 The influence of antiscatter grids on soft-tissue detectability in cone-beam computed tomography with flat-panel detectors Med. Phys. 31 3506-3520

Sillanpaa J, Chang J, Mageras G, Riem H, Ford E, Todor D, Ling C C and Amols H 2005 Developments in megavoltage cone beam CT with an amorphous silicon EPID: Reduction of exposure and synchronization with respiratory gating Med. Phys. 32 819-829

Simpson R G, Chen C T, Grubbs E A and Swindell W 1982 A 4-MV CT scanner for radiation-therapy - the prototype system Med. Phys. 9 574-579

Sixel K E, Ruschin M, Tirona R and Cheung P C F 2003 Digital fluoroscopy to quantify lung tumor motion: Potential for patient-specific planning target volumes Int. J. Radiat. Oncol. Biol. Phys. 57 717-723

Soete G, Van de Steene J, Verellen D, Vinh-Hung V, Van den Berge D, Michielsen D, Keuppens F, De Roover P and Storme G 2002 Initial clinical experience with infrared-reflecting skin markers in the positioning of patients treated by conformal radiotherapy for prostate cancer Int. J. Radiat. Oncol. Biol. Phys. 52 694-698

Sonke J J, Zijp L, Remeijer P and van Herk M 2005 Respiratory correlated cone beam CT Med. Phys. 32 1176-1186

Sontag M R and Cunningham J R 1978 The equivalent tissue-air ratio method for making absorbed dose calculations in a heterogeneous media Radiology 129 787- 794

Spezi E and Lewis D G 2002 Full forward Monte Carlo calculation of portal dose from MLC collimated treatment beams Phys. Med. Biol. 47 377-390

Spies L, Evans PM, Partridge M, Hansen VN and Bortfeld T 2000 Direct measurement and analytical modeling of scatter in portal imaging Med. Phys. 27 462-471 
Stock RG, Chan K, Terk M, Dewyngaert J K, Stone N N and Dottino P 1997 A new technique for performing Syed-Neblett template interstitial implants for gynecologic malignancies using transrectal-ultrasound guidance Int. J. Radiat. Oncol. Biol. Phys. 37 819-825

Storaas T, Gjesdal K I, Svindland A, Viktil E and Geitung J T 2004 Dynamic first pass 3D EPI of the prostate: Accuracy in tumor location Acta Radiologica 45 584-590

Stroom J C, de Boer H C J, Huizenga H and Visser AG 1999 Inclusion of geometrical uncertainties in radiotherapy treatment planning by means of coverage probability Int. J. Radiat. Oncol. Biol. Phys. 43 905-919

Sumi M, Sakihama N, Sumi T, Morikawa M, Uetani M, Kabasawa H, Shigeno K, Hayashi K, Takahashi H and Nakamura T 2003 Discrimination of metastatic cervical lymph nodes with diffusion-weighted MR imaging in patients with head and neck cancer Am. J. Neuroradiol. 24 $1627-1634$

Swindell W 1983 A 4-MV CT scanner for radiation-therapy - spectral properties of the therapy beam Med. Phys. 10 347-351

Sykes J R, Amer A, Czajka J and Moore C J 2005 A feasibility study for image guided radiotherapy using low dose, high speed, cone beam X-ray volumetric imaging Radiother. Oncol. 77 45-52

Tan P N, Steinbach M and Kumar V 2005 Introduction to Data Mining (Boston: Addison-Wesley Longman)

Tanner S F, Finnigan D J, Khoo V S, Mayles P, Dearnaley D P and Leach M O 2000 Radiotherapy planning of the pelvis using distortion corrected MR images: the removal of system distortions Phys. Med. Biol. 45 2117-2132

Teefey S A, Hildeboldt C C, Dehdashti F, Siegel B A, Peters M G, Heiken J P, Brown J J, McFarland E G, Middleton W D, Balfe D M and Ritter JH 2003 Detection of primary hepatic malignancy in liver transplant candidates: Prospective comparison of CT, MR imaging US and PET Radiology 226 533-542

Ten Haken R K, Thornton A F, Sandler H M, Lavigne M L, Quint D J, Fraass BA, Kessler M L and McShan DL 1992 A quantitative assessment of the addition of mri to ct-based, 3-d treatment planning of brain-tumors Radiother. Oncol. 25121-133

Treece G M, Prager R W, Gee A H and Berman L 2002 Correction of probe pressure artifacts in freehand 3D ultrasound Med. Image Anal. 6 199-214

Treece G M, Gee A H, Prager R W, Cash C J C and Berman L H 2003 High-definition freehand 3-D ultrasound Ultrasound Med. Biol. 29 529-546

Trichter F and Ennis RD 2003 Prostate localization using transabdominal ultrasound imaging Int. J. Radiat. Oncol. Biol. Phys. 56 1225-1233

Underberg R W M, Lagerwaard F J, Cuijpers J P, Slotman B J, de Koste J R V and Senan S 2004 Fourdimensional ct scans for treatment planning in stereotactic radiotherapy for stage I lung cancer Int. J. Radiat. Oncol. Biol. Phys. 60 1283-1290

Van de Steene J, Linthout N, de Mey J, Vinh-Hung V, Claassens C, Noppen M, Bel A and Storme G 2002 Definition of gross tumor volume in lung cancer: inter-observer variability Radiother. Oncol. 62 37-49

Van den Heuvel F, Powell T, Seppi E, Littrupp P, Khan M, Wang Y and Forman J D 2003 Independent verification of ultrasound based image-guided radiation treatment, using electronic portal imaging and implanted gold markers Med. Phys. 30 2878-2887

van der Geld Y G, Senan S, de Koste J R V, van Tinteren H, Slotman B J, Underberg R W M, Lagerwaard F J 2006 Evaluating mobility for radiotherapy planning of lung tumors: A comparison of virtual fluoroscopy and 4DCT Lung Cancer 53 31-37

Van Esch A, Depuydt T and Huyskens D P 2004 The use of an aSi-based EPID for routine absolute dosimetric pre-treatment verification of dynamic IMRT fields Radiother. Oncol. 71 223-234

van Herk M, Remeijer P, Rasch C, Lebesque JV 2000 The probability of correct target dosage: Dosepopulation histograms for deriving treatment margins in radiotherapy Int. J. Radiat. Oncol. Biol. Phys. 47 1121-1135

van Herk M 2004 Errors and margins in radiotherapy Semin. Radiat. Oncol. 14 52-64

Van Herk M and Lomax A 2007 Have we forgotten about the ALARA principle in IGRT? Radiother. Oncol. 84 S54

Vedam S S, Keall P J, Kini V R and Mohan R 2001 Determining parameters for respiration-gated radiotherapy Med. Phys. 28 2139-2146

Verhaegen F, Seuntjens J 2003 Monte Carlo modelling of external radiotherapy photon beams Phys. Med. Biol. 48 R107-R164

Verhaegen F and Devic S 2005 Sensitivity study for CT image use in Monte Carlo treatment planning Phys. Med. Biol. 50 937-946 
Vigneault E, Pouliot J, Laverdiere J, Roy J and Dorion M 1997 Electronic portal imaging device detection of radioopaque markers for the evaluation of prostate position during megavoltage irradiation: A clinical study Int. J. Radiat. Oncol. Biol. Phys. 37 205-212

Wagman R, Yorke E, Ford E, Giraud P, Mageras G, Minsky B, Rosenzweig K 2003 Respiratory gating for liver tumors: Use in dose escalation Int. J. Radiat. Oncol. Biol. Phys. 55 659-668

Wang Y, Cardinal N, Downey D B and Fenster A 2003 Semiautomatic three-dimensional segmentation of the prostate using two-dimensional ultrasound images Med. Phys. 30 887-897

Wang D, Strugnell W, Cowin G, Doddrell DM and Slaughter R 2004a Geometric distortion in clinical MRI systems - Part I: evaluation using a 3D phantom Magn. Reson. Imaging 22 1211-1221

Wang D, Strugnell W, Cowin G, Doddrell DM and Slaughter R 2004b Geometric distortion in clinical MRI systems - Part II: correction using a 3D phantom Magn. Reson. Imaging 22 1223-1232

Wang DM, Doddrell DM and Cowin G 2004c A novel phantom and method for comprehensive 3dimensional measurement and correction of geometric distortion in magnetic resonance imaging Magn. Reson. Imaging 22 529-542

Warkentin B, Steciw S, Rathee S and Fallone B G 2003 Dosimetric IMRT verification with a flat-panel EPID Med. Phys. 30 3143-3155

Webb S 1989 Optimization of conformal radiotherapy dose distributions by simulated annealing Phys. Med. Biol. 34 1349-1370

Webb S 1993 The Physics of Three-dimensional Radiation Therapy, chapter 1 (London: Taylor and Francis)

Webb S 2000 Intensity Modulated Radiation Therapy (London: Taylor and Francis)

Webb S 2005 The effect on IMRT conformality of elastic tissue movement and a practical suggestion for movement compensation via the modified dynamic multileaf collimator (dMLC) technique Phys. Med. Biol. 50 1163-1190

Weiss E, Richter S, Krauss T, Metzelthin S I, Hille A, Pradier O, Siekmeyer B, Vorwerk H and Hess CF 2003 Conformal radiotherapy planning of cervix carcinoma: differences in the delineation of the clinical target volume. A comparison between gynaecologic and radiation oncologists Radiother. Oncol. 67 87-95

Weltens C, Menten J, Feron M, Bellon E, Demaerel P, Maes F, Van den Bogaert W and van der Schueren E 2001 Interobserver variations in gross tumor volume delineation of brain tumors on computed tomography and impact of magnetic resonance imaging Radiother. Oncol. 60 49-59

Wendling M, Louwe R J W, McDermott L N, Sonke J J, van Herk M and Mijnheer B J 2006 Accurate two-dimensional IMRT verification using a back-projection EPID dosimetry method Med. Phys. 33 259-273

Wenz F, Rempp K, Hess T, Debus J, Brix G, Engenhart R, Knopp MV, vanKaick G and Wannenmacher M 1996 Effect of radiation on blood volume in low-grade astrocytomas and normal brain tissue: Quantification with dynamic susceptibility contrast MR imaging Am. J. Roentgenol. 166 187-193

White E A, Cho J, Vallis K A, Sharpe M B, Lee G, Blackburn H, Nageeti T, McGibney C and Jaffray D A 2007 Cone beam computed tomography guidance for setup of patients receiving accelerated partial breast irradiation Int. J. Radiat. Oncol. Biol. Phys. 68 547-554

Wilks R J and Bliss P 2002 The use of a compensator library to reduce dose inhomogeneity in tangential radiotherapy of the breast Radiother. Oncol. 62 147-157

Willoughby T R, Kupelian P A, Pouliot J, Shinohara K, Aubin M, Roach M, Skrumeda L L, Balter J M, Litzenberg D W, Hadley S W, Wei J T and Sandler H M 2006 Target localization and realtime tracking using the calypso 4D localization system in patients with localized prostate cancer Int. J. Radiat. Oncol. Biol. Phys. 65 528-534

Winkler P, Hefner A and Georg D 2005 Dose-response characteristics of an amorphous silicon EPID Med. Phys. 32 3095-3105

Wolthaus J W H, van Herk M, Muller S H, Belderbos J S A, Lebesque J V, de Bois J A, Rossi M M G and Damen E M F 2005 Fusion of respiration-correlated PET and CT scans: correlated lung tumour motion in anatomical and functional scans Phys. Med. Biol. 50 1569-1583

Wolthaus J W H, Schneider C, Sonke J-J et al 2006 Mid-ventilation CT scan construction from fourdimensional respiration-correlated CT scans for radiotherapy planning of lung cancer patients Int J Radiat Oncol Biol Phys; 65 1560-1571.

Wong J W, Sharpe M B, Jaffray D A, Kini V R, Robertson J M, Stromberg J S and Martinez A A 1999 The use of active breathing control $(\mathrm{ABC})$ to reduce margin for breathing motion Int. J. Radiat. Oncol. Biol. Phys. 44 911-919 
Wurstbauer K, Deutschmann H, Kopp P and Sedlmayer F 2005 Radiotherapy planning for lung cancer: Slow CTs allow the drawing of tighter margins Radiother. Oncol. 75 165-170

Yan D, Ziaja E, Jaffray D, Wong J, Brabbins D, Vicini F and Martinez A 1998 The use of adaptive radiation therapy to reduce setup error: A prospective clinical study Int. J. Radiat. Oncol. Biol. Phys. 41 715-720

Yan Y L, Song Y L and Boyer A L 2002 An investigation of a video-based patient repositioning technique Int. J. Radiat. Oncol. Biol. Phys. 54 606-614

Yarnold J, Ashton A, Bliss J, Homewood J, Harper C, Hanson J, Haviland J, Bentzen S and Owen R 2005 Fractionation sensitivity and dose response of late adverse effects in the breast after radiotherapy for early breast cancer: long-term results of a randomised trial Radiother. Oncol. 75 9-17

Yin F F, Ryu S, Ajlouni M, Zhu J G, Yan H, Guan H, Faber K, Rock J, Abdalhak M, Rogers L, Rosenblum M and Kim J H 2002 A technique of intensity-modulated radiosurgery (IMRS) for spinal tumors Med. Phys. 29 2815-2822

Yin F F, Guan H Q and Lu W K 2005 A technique for on-board CT reconstruction using both kilovoltage and megavoltage beam projections for 3D treatment verification Med. Phys. 32 2819-2826

Yoo S and Yin F F 2006a Dosimetric feasibility of cone-beam CT-based treatment planning compared to CT-based treatment planning Int. J. Radiat. Oncol. Biol. Phys. 66 1553-1561

Yoo S, Kim G Y, Hammoud R, Elder E, Pawlicki T, Guan H Q, Fox T, Luxton G, Yin F F and Munro P 2006b A quality assurance program for the on-board imager Med. Phys. 33 4431-4447

Zamorano L, Dujovny M, Malik G, Yakar D and Mehta B 1987 Multiplanar CT-guided stereotaxis and I125 interstitial radiotherapy - image-guided tumor volume assessment, planning, dosimetric calculations, stereotactic biopsy and implantation of removable catheters Appl Neurophysiol. 50 281-286

Zhang Y B, Zhang L F, Zhu R, Lee A K, Chambers M and Dong L 2007 Reducing metal artifacts in cone-beam CT images by preprocessing projection data Int. J. Radiat. Oncol. Biol. Phys. 67 924-932

Zhao H, Hubenschmidt J, Malinowski K and Parikh P 2007 Initial phantom evaluation of a surface imaging system (GateCT ®) for 4-D CT Med. Phys. 34 2554-2554 


\section{Table Caption}

Table 1: Summary of properties of imaging methods used for image guided radiotherapy. MV denotes megavoltage and $\mathrm{kV}$ kilovoltage. 


\section{Figure Captions}

Figure 1: Isosurface rendering of a spherical object, CT scanned while periodically moving on a sliding table. Top row: different artefacts obtained by standard axial CT scanning starting at different motion phases. Bottom row: left shows a CT scan of the static object. Other images show 3 positions of the sphere while moving as imaged with 4DCT. Reproduced with kind permission from Rietzel et al. 2005b.

Figure 2: Illustration of the planning target volume (PTV, left) and confidencelimited planning target volume (cl-PTV, right) on the sagittal CT scan of a patient, and the corresponding treated volume (gray shaded area) on the beam's eye view digitally reconstructed radiograph. Pink shows prostate, rectum yellow and bladder green. Reproduced with kind permission from Martinez et al. 2001.

Figure 3: Illustration of a perfusion study for head and neck cancer. a) shows a transaxial CT slice with various regions of interest (ROIs) marked. b) shows measured CT number as a function of time for a selection of the ROIs. The ROIs are: arterial input (1), tumour (2, 7 and 8) sternocleidomastoid muscles (SCM) (3 and 6) and trapezius muscles (TZ) (4 and 5). Reproduced with kind permission from Castellano 2006.

Figure 4: $\mathrm{CT}$ image of a prostate with an implanted fiducial marker showing typical metal artefacts (A). B) and C) show the results of two methods of artefact correction. Reproduced with kind permission from Bal and Spies 2006.

Figure 5: CT slice through a prostate (a) and the corresponding MR scan (b). Reproduced with kind permission from Khoo et al. 2006.

Figure 6: Gross tumour volume delineations of nine observers on transaxial CT (left) and transaxial MRI (right). Reproduced with kind permission from Weltens et al. 2001.

Figure 7: Linearity test phantom (left) and an uncorrected coronal MRI scan acquired from this phantom (right). The spots within the image arise from a regular lattice of water-filled marker tubes. Image distortion is evident from the irregular positioning of the spots and warping out of the plane of the image is seen in the appearance and disappearance of the straight marker tubes lying in the imaging plane. This image was acquired at the periphery of the imaging volume and hence distortion is particularly severe in this case. Reproduced with kind permission from Tanner et al. 2000.

Figure 8: Fluoroscopic real-time tumour tracking system, showing three of the four fluoroscopy systems. Reproduced with kind permission from Shirato et al. 2000a.

Figure 9: Sagittal conebeam CT slice through a prostate patient. The image shows various soft tissue features: bladder $(\mathrm{B})$, prostate $(\mathrm{P})$, seminar vesicles $(\mathrm{SV})$, rectum (R) and sigmoid colon (S). Reproduced with kind permission from Létourneau et al. 2005. 